\title{
Geostrophic Circulation in the Tropical North Pacific Ocean Based on Argo Profiles
}

\author{
DONGLIANG YUAN \\ Key Laboratory of Ocean Circulation and Waves, and Institute of Oceanology, Chinese Academy of Sciences, \\ and Qingdao Collaborative Innovation Center of Marine Science and Technology, Qingdao, China \\ ZHICHUN ZHANG \\ Key Laboratory of Ocean Circulation and Waves, and Institute of Oceanology, Chinese Academy of Sciences, Qingdao, and \\ Department of Ocean Science and Engineering, Zhejiang University, Hangzhou, and State Key Laboratory of Tropical \\ Oceanography, South China Sea Institute of Oceanology, Chinese Academy of Sciences, Guanzhou, China \\ Peter C. Chu \\ Naval Ocean Analysis and Prediction Laboratory, Department of Oceanography, Naval Postgraduate School, Monterey, California \\ WILLIAM K. DEWAR \\ Department of Ocean, Atmosphere and Earth Sciences, The Florida State University, Tallahassee, Florida
}

(Manuscript received 28 November 2012, in final form 6 November 2013)

\begin{abstract}
Absolute geostrophic currents in the North Pacific Ocean are calculated from the newly gridded Argo profiling float data using the P-vector method for the period of 2004-11. The zonal geostrophic currents based on the Argo profile data are found to be stronger than those based on the traditional World Ocean Atlas 2009 (WOA09) data. A westward mean geostrophic flow underneath the North Equatorial Countercurrent is identified using the Argo data, which is evidenced by sporadic direct current measurements and geostrophic calculations in history. This current originates east of the date line and transports more than $4 \times 10^{6} \mathrm{~m}^{3} \mathrm{~s}^{-1}$ of water westward in the subsurface northwestern tropical Pacific Ocean. The authors name this current the North Equatorial Subsurface Current. The transport in the geostrophic currents is compared with the Sverdrup theory and found to differ significantly in several locations. Analyses have shown that errors of wind stress estimation cannot account for all of the differences. The largest differences are found in the area immediately north and south of the bifurcation latitude of the North Equatorial Current west of the date line and in the recirculation area of the Kuroshio and its extension, where nonlinear activities are vigorous. It is, therefore, suggested that the linear dynamics of the Sverdrup theory is deficient in explaining the geostrophic transport of the tropical northwestern Pacific Ocean.
\end{abstract}

\section{Introduction}

The alternating zonal currents of the low-latitude North Pacific Ocean have long been recognized by the oceanographic community based on ship drift data and sporadic hydrographic surveys (Schott 1939; Reid 1961; Wyrtki 1961). The upper-ocean circulation was suggested by Sverdrup (1947) to be forced by the curl of the

\footnotetext{
Corresponding author address: Dongliang Yuan, Institute of Oceanology, Chinese Academy of Sciences, 7 Nanhai Rd., Qingdao, 266071, China.

E-mail: dyuan@ms.qdio.ac.cn
}

wind stress through the so-called Sverdrup balance. The theory assumes a linear dynamic framework and has obtained the meridional transport of the wind-driven ocean circulation by integrating the wind stress curl without detailed information of the oceanic baroclinicity. The zonal transport of the wind-driven circulation is then obtained by integrating the streamfunction from the eastern boundary of the North Pacific Ocean. Because of the lack of sufficient measurements to estimate the mean circulation accurately, the validity of the theory has not previously been tested in the North Pacific Ocean.

A few studies have, however, have attempted to verify the accuracy of the theory in the Atlantic Ocean. The 
first was that of Leetmaa et al. (1977), which inspired the studies of Wunsch and Roemmich (1985), Böning et al. (1991), Schmitz et al. (1992), and so on. These studies have shown that the Sverdrup meridional transport is generally consistent with the meridional transport calculated directly from the geostrophic currents based on hydrographic data in the northeastern subtropical North Atlantic Ocean, but is inconsistent with the geostrophic transports in the northwestern subtropical North Atlantic Ocean. The difference has been attributed to buoyancy-forced meridional overturning circulation in the North Atlantic Ocean.

In the Pacific Ocean, Meyers (1980) discussed the meridional transport of the North Equatorial Countercurrent (NECC) and found significant inconsistency with the Sverdrup theory. Hautala et al. (1994) estimated the meridional transport of the North Pacific subtropical gyre along $24^{\circ} \mathrm{N}$ and noted that the Sverdrup balance is not valid in the western subtropical Pacific Ocean. The two studies are still very limited in disclosing the basin-scale differences from the Sverdrup theory, and neither of the studies has elaborated on the reasons of the inconsistency.

All of the above existing evaluations of the Sverdrup balance are based on one-time hydrographic measurements in a cross-basin section and have only been able to evaluate the accuracy of the theory in an integrated meridional transport from the eastern boundary. Lately, Wunsch (2011) has evaluated the accuracy of the Sverdrup theory using an assimilated global ocean dataset. A pointwise evaluation of the Sverdrup balance in the real ocean is highly desired but has not been fulfilled so far due to the sparse and uneven distribution of hydrographic casts in time and space of the world's oceans, which will inevitably bring significant aliasing errors into the mean circulation and meridional transport.

By far the largest zonal surface current in the tropical North Pacific Ocean is the North Equatorial Current (NEC) flowing westward across the Pacific basin in the latitudinal band of roughly $7^{\circ} \sim 20^{\circ} \mathrm{N}$ (Wyrtki 1961; Nitani 1975). On both sides of NEC are two eastward currents called NECC in the south and the Subtropical Countercurrent (STCC) in the north. Existing studies of these zonal currents are based primarily on hydrography measurements conducted with uneven temporal and spatial distributions. Good estimates of the three-dimensional mean structure and the seasonalto-interannual variations of these currents at the basin scales have not been achieved in the past.

So far, there have been several methods to estimate geostrophic currents from the temperature and salinity profile data, such as the traditional dynamic height calculation in reference to a level of no motion, the $\beta$-spiral method of Stommel and Schott (1977), the box inverse method of Wunsch (1978), and the P-vector method of Chu (1995). The traditional dynamic height calculation is simple, but cannot obtain the absolute geostrophic currents due to the use of a reference level. This major disadvantage has promoted the invention of more objective methods, such as the $\beta$-spiral method, the box inverse method, and the P-vector method, to determine the absolute geostrophic currents. The $\beta$-spiral method is based on the conservation of mass, density, and planetary vorticity to estimate the reference velocities (Stommel and Schott 1977; Schott and Stommel 1978). Although the algorithm forms an overdetermined problem (the number of equations is larger than the number of unknowns) when multiple levels of hydrographic data are used, the calculated geostrophic currents are generally noisy due to the use of second-order derivatives of the potential density surfaces in the calculation. The box inverse method estimates the reference velocities by balancing the fluxes of water and tracers into and out of a closed region (Wunsch 1978). However, this method forms an underdetermined system (the number of equations is less than the number of unknowns) and is most applicable for ship-based surveys in a small region. The P-vector method assumes conservation of potential vorticity and density and forms an overdetermined system if multiple levels of hydrographic data are used. Dynamically, the $\mathrm{P}$-vector method is equivalent to the $\beta$-spiral method under the Boussinesq and geostrophic approximation (appendix A), but is able to control the errors of the calculation well through the use of the potential density gradients only (Chu 1995, 2000; Chu et al. 1998, 2001).

The advent of the Argo project in the world's oceans has ushered in an unprecedented era of sampling the world's oceans with synchronicity at basin and global scales. These data can be used to study the general circulation at basin and global scales and to evaluate the accuracy of the Sverdrup balance. In this study, we calculate the absolute geostrophic currents (AGC) in the North Pacific Ocean based on the newly gridded Argo profiling float data using the P-vector method. The three-dimensional structure of the mean circulation is then studied and the meridional transport of the geostrophic currents is calculated to evaluate the accuracy of the Sverdrup theory.

In section 2, the data and the P-vector method used in this study are introduced. In section 3, the accuracy of the AGC is assessed using altimeter data and in situ mooring measurements in the North Pacific Ocean. The three-dimensional structure of the alternating zonal currents is studied, and the transport of the mean geostrophic currents is computed and compared with the Sverdrup theory. The error estimates and the sensitivity of the geostrophic transports with respect to the 
depth of integration and wind products are discussed in section 4. Conclusions are summarized in section 5.

\section{Data and method}

\section{a. Data}

The gridded Argo data used in this study are obtained from the Argo website (http://www.argo.ucsd.edu/ Gridded_fields.html). The product name is the global gridded Network Common Data Form (NetCDF) Argoonly dataset produced by optimal interpolation, which includes salinity and temperature data on a $1^{\circ} \times 1^{\circ}$ horizontal grid and at 58 vertical levels. These temperature and salinity data are collected by Argo floats deployed into the world's oceans, which drift for a number of years making measurements of temperature and salinity profiles of the ocean at 10-day cycles. These profiles are then quality controlled, interpolated onto the regular grid, and archived in monthly-mean files for scientific use. In this study, we use the profiles averaged from January 2004 to December 2011 (Roemmich and Gilson 2009). Besides the Argo data, the climatological average of the World Ocean Atlas 2009 (WOA09) temperature (Locarnini et al. 2010) and salinity (Antonov et al. 2010) data is also used for comparison.

The in situ measurements of ocean currents by acoustic Doppler current profiler (ADCP) current meters deployed at the 10-m depth at the Tropical Atmosphere Ocean (TAO)/Triangle Trans-Ocean Buoy Network (TRITON) sites of $8^{\circ} \mathrm{N}, 137^{\circ} \mathrm{E}$ and $8^{\circ} \mathrm{N}, 156^{\circ} \mathrm{E}$, respectively, are used to evaluate the accuracy of the AGC calculated by the P-vector method. Assuming a vertical viscosity of $0.012 \mathrm{~m}^{2} \mathrm{~s}^{-1}$, which corresponds to a surface Ekman layer thickness of $91 \mathrm{~m}$, the Ekman spiral is calculated, using the National Centers for Environmental Prediction (NCEP) wind data and the drag coefficient of Large and Pond (1981), and is subtracted from the current-meter time series at $10 \mathrm{~m}$. Because the Ekman layer thickness is much larger than $10 \mathrm{~m}$, the surface Ekman velocity is not sensitive to the choice of the vertical viscosity coefficient. The hourly currentmeter time series are averaged into monthly-mean data to be compared with the altimeter and P-vector geostrophic currents.

In addition, the surface geostrophic currents based on the merged altimeter sea level data of the French Archiving, Validation, and Interpolation of Satellite Oceanographic Data (AVISO) project collected by the Ocean Topography Experiment (TOPEX)/Poseidon, Jason-1, and European Research Satellites are used to evaluate the P-vector AGC. The altimeter data are archived on a global grid of $1 / 3^{\circ}$ resolution between $82^{\circ} \mathrm{S}$ and $82^{\circ} \mathrm{N}$ at weekly intervals with tidal and sea level atmospheric pressure corrections incorporated. The geostrophic currents are calculated from the absolute dynamic topography, which consists of a mean dynamic topography (Rio and Hernandez 2004) and the anomalies of the altimeter sea level, and are averaged into monthly-mean data at $1^{\circ}$ longitude by $1^{\circ}$ latitude resolution to be compared with the AGC at the surface. The AVISO sea level data can be accessed online (http:// www.aviso.oceanobs.com/).

The monthly climatological data of the Ocean General Circulation Model for the Earth Simulator (OFES) (Masumoto et al. 2004) averaged from the last 10-year simulation of a 50-year model spinup forced by the climatological NCEP-National Center for Atmospheric Research (NCAR) reanalysis data are used to examine the Sverdrup theory as well. The OFES domain covers the global ocean from $75^{\circ} \mathrm{S}$ to $75^{\circ} \mathrm{N}$, with a horizontal resolution of $0.1^{\circ}$ longitude $\times 0.1^{\circ}$ latitude and stretched vertical coordinates of 54 levels from the sea surface $(2.5 \mathrm{~m})$ to a maximum depth of $6065 \mathrm{~m}$.

The NCEP-NCAR reanalysis wind velocity products and the 40-yr European Centre for Medium-Range Weather Forecasts (ECMWF) Re-Analysis (ERA-40) wind velocity are used to calculate the Sverdrup transport in this study. The wind stress is calculated based on the quadratic drag law using the different drag coefficients of Garratt (1977), Large and Pond (1981), and Foreman and Emeis (2010), respectively, to test the sensitivity of the Sverdrup transport in this paper.

\section{b. Absolute geostrophic currents}

The AGC in this study are calculated from gridded temperature and salinity data using the P-vector method (appendix B), which is based on the conservation of potential density and potential vorticity under three approximations: the geostrophic balance, adiabatic flow, and the Boussinesq approximation (Chu 1995, 2006). The intersection of isopycnal and equal potential vorticity surfaces determines the direction of the geostrophic currents, which is called the $\mathrm{P}$ vector. The thermal wind vector between any two levels can be used to calculate the magnitude of the geostrophic currents at the two levels. In practice, the geostrophic currents are determined by least squares fittings to the data at multiple levels (Chu 1995, 2000; Chu et al. 1998, 2001).

In the past (e.g., Chu 1995), the P-vector geostrophic currents were computed by applying the least squares fitting in the whole water column of the ocean. Because the conservation of density and potential vorticity is generally not accurate in the upper mixed layer of the ocean, we chose to construct the geostrophic currents only in the intermediate layers (Zhang 2011; Zhang et al. 2013); 


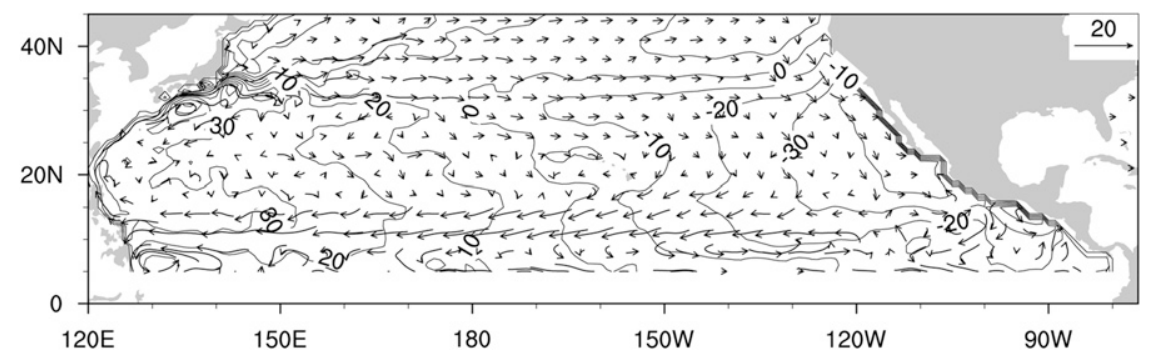

FIG. 1. The 2004-11 mean Argo dynamic height (contours; cm) relative to 1500-m depth with the spatial average removed and surface AGC (vectors; $\mathrm{cm} \mathrm{s}^{-1}$ ).

that is, the P-vector method is used to calculate the geostrophic currents between 800 and 2000 dbar. The geostrophic currents above 800 dbar are determined by the dynamic height calculation, using the geostrophic currents at 800 dbar as the reference velocity. Experiments have shown that AGC are not sensitive to the choices of the depth ranges mentioned above as long as the $\mathrm{P}$-vector calculation is conducted significantly below the surface mixed layer.

The errors of the geostrophic currents are estimated based on the thermal wind relation and the standard deviation of the density, assuming that the largest errors of the currents occur when density errors are out of phase at the adjacent grid points. In addition, the errors of the mean circulation are augmented by the standard deviation of the P-vector geostrophic currents so that the time dependency of the ocean circulation is included in the error estimate. Errors of the meridional transports at each grid are obtained by vertical integrations from $1900 \mathrm{~m}$ to the sea surface.

\section{c. The Sverdrup balance}

The Sverdrup theory assumes linear, geostrophic dynamics and the existence of a maximum depth $H$ in the ocean, beyond which the horizontal and vertical velocities vanish (Sverdrup 1947). The vertically integrated momentum and continuity are governed by the following equations:

$$
\begin{aligned}
-\frac{\partial P}{\partial x} & =-f V+\frac{\tau^{x}}{\rho}, \\
-\frac{\partial P}{\partial y} & =f U+\frac{\tau^{y}}{\rho}, \text { and } \\
\frac{\partial U}{\partial x}+\frac{\partial V}{\partial y} & =0,
\end{aligned}
$$

where the notations are conventional, $f$ is the Coriolis parameter, and $U, V$, and $P$ stand for vertically integrated horizontal velocities and pressure from $-H$ to 0 .
Cross-differentiating the first two equations and using the third, the Sverdrup relation is obtained as the following:

$$
\beta V=\frac{1}{\rho}\left(\frac{\partial \tau^{x}}{\partial y}-\frac{\partial \tau^{y}}{\partial x}\right)
$$

where $\rho$ is the water density, $\tau^{x}$ and $\tau^{y}$ are the wind stress components, and $\beta=d f / d y$ is the meridional gradient of the Coriolis parameter. Sverdrup (1947) assumes that the vertical velocity $w$ vanishes at the depth $z=-H$. In this paper, $H$ is chosen to be the maximum depth of the Argo float measurements of $1900 \mathrm{~m}$ or at some specified isopycnal (see section $4 \mathrm{c}$ ). The vertically integrated meridional transport in Eq. (2) includes the surface Ekman transport and the geostrophic transport. The integration of the meridional geostrophic transport along a latitude $y$ from the eastern boundary $x_{E}$ to a longitude $x$ is calculated by

$$
\int_{x_{E}}^{x} \int_{-H}^{0} V_{g} d x d z=\frac{1}{\beta \rho} \int_{x_{E}}^{x}\left(\frac{\partial \tau^{x}}{\partial y}-\frac{\partial \tau^{y}}{\partial x}\right) d x+\frac{1}{f \rho} \int_{x_{E}}^{x} \tau^{x} d x
$$

Both sides of Eq. (3) vary with $x$ and $y$. The left side is called the geostrophic meridional transport (calculated from ocean hydrographic data). The right side is the meridional Sverdrup minus Ekman transport $(S-E$ transport in abbreviation) computed from surface wind stress. The traditional Sverdrup transport is the first term on the right side of the Eq. (3).

\section{Results}

\section{a. Validation of the P-vector AGC}

Figure 1 shows the average surface dynamic topography with the spatial average removed and the average surface AGC for the period of 2004-11 in the North Pacific Ocean. The geostrophic currents at the sea surface are characterized by NEC in the latitudinal range of $7^{\circ}-20^{\circ} \mathrm{N}, \mathrm{NECC}$ south of $7^{\circ} \mathrm{N}, \mathrm{STCC}$ along roughly $25^{\circ} \mathrm{N}$, 

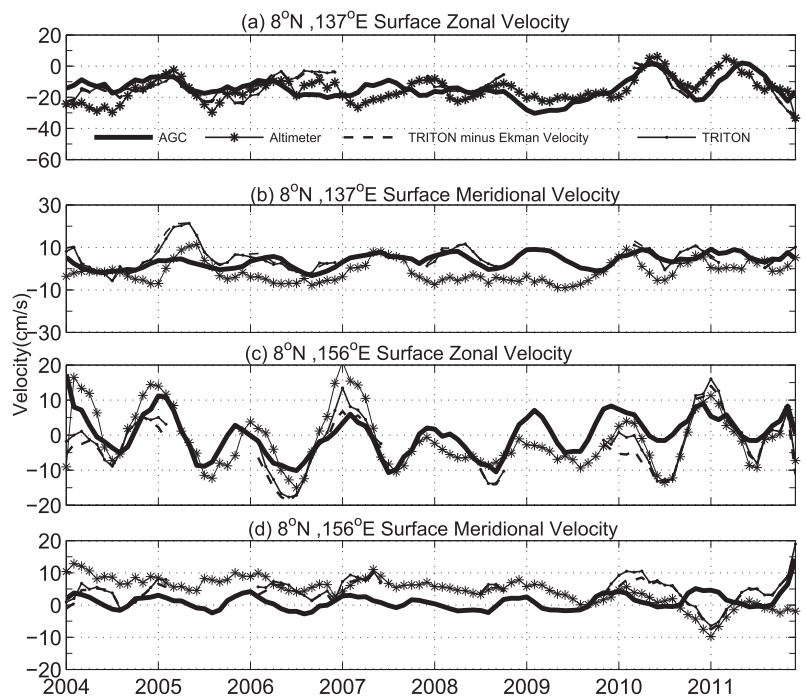

FIG. 2. Comparison of Argo surface AGC (thick curve) with the direct current-meter measurements of the TRITON array at $10-\mathrm{m}$ depth (thin curve) and the geostrophic currents based on the absolute dynamic topography of satellite altimetry at the same location (curve with asterisks) for (a),(b) $8^{\circ} \mathrm{N}, 137^{\circ} \mathrm{E}$ and (c),(d) $8^{\circ} \mathrm{N}, 156^{\circ} \mathrm{E}$. The current-meter velocity components with the surface Ekman velocity removed are shown in dashed curves for comparison.

and the Kuroshio Extension (KE) east of Japan, which are consistent with the historical understanding of the alternating zonal currents in the area. Because of the coarse resolution of the gridded data, the western boundary currents near the coasts of the Philippines and in the East China Sea are not well resolved by the calculation.

Comparison of the P-vector AGC at the sea surface with altimeter geostrophic currents and with TRITON moored current-meter data at $10 \mathrm{~m}$ at $8^{\circ} \mathrm{N}, 137^{\circ} \mathrm{E}$ and at $8^{\circ} \mathrm{N}, 156^{\circ} \mathrm{E}$ is shown in Fig. 2. The current-meter time series with and without the Ekman velocity are both shown, the difference of which is small due to the weak easterlies at this latitude. The agreement among the $\mathrm{P}$-vector calculation, altimeter geostrophy, and the direct current measurement is reasonable. At $8^{\circ} \mathrm{N}, 137^{\circ} \mathrm{E}$, the root-mean-square (RMS) difference of zonal currents between the AGC and current meter is $7.32 \mathrm{~cm} \mathrm{~s}^{-1}$-larger than the $5.75 \mathrm{~cm} \mathrm{~s}^{-1}$ between the altimeter and the current meter. Also the correlation coefficient of zonal currents between the AGC and the current meter is 0.38-smaller than the 0.755 between the altimeter and the current meter. However, both correlations are close to or above the $95 \%$ significance level (Table 1). The significance level of correlation in this paper is based on the decorrelation time scales estimated using the method of Davis (1976) and Kessler et al. (1996). In contrast, the meridional component of AGC is in better agreement with the current-meter data than are the altimetric geostrophic currents. The latter has systematically underestimated the meridional transport of the ocean during the observational period. The correlation coefficient of meridional currents between the AGC and the current meter is 0.59 , in comparison with the correlation coefficient of 0.559 between the altimeter and the current meter, both of which are above the $95 \%$ significance level. The RMS difference of the AGC meridional currents from the current-meter data is $4.05 \mathrm{~cm} \mathrm{~s}^{-1}$ - smaller than the $4.55 \mathrm{~cm} \mathrm{~s}^{-1}$ between the altimeter meridional currents and the current-meter data.

At $8^{\circ} \mathrm{N}, 156^{\circ} \mathrm{E}$, the RMS difference of zonal currents between the AGC and current meter is $5.27 \mathrm{~cm} \mathrm{~s}^{-1}$ smaller than the $6.49 \mathrm{~cm} \mathrm{~s}^{-1}$ between the altimeter and the current meter. The correlation coefficient of zonal currents between the AGC and the current meter is 0.66 - above the $95 \%$ significance level and comparable to that of 0.79 , also above the $95 \%$ significance level, between the altimeter and the current meter. The systematic difference between the altimeter and the AGC meridional velocity is still glaringly large. During the winter of 2010/11, the Argo meridional currents show out-of-phase variations from the current-meter and altimeter data that are induced by what appears to be a displaced stationary eddy in the vicinity of $8^{\circ} \mathrm{N}, 156^{\circ} \mathrm{E}$ in the Argo data (Fig. 3). It is possible that the discrepancy is due to the gridding and interpolation of the sparse Argo data in the area. Otherwise, the limited current-meter data seem to suggest that the AGC is a reasonable estimate of the local geostrophic currents. The correlation coefficient of meridional currents

TABLE 1. Correlation coefficients between Argo geostrophic currents and the current-meter velocity and between the altimeter geostrophic currents and the current-meter velocity at $8^{\circ} \mathrm{N}, 137^{\circ} \mathrm{E}$ and $8^{\circ} \mathrm{N}, 156^{\circ} \mathrm{E}$, respectively. The value in parentheses denotes the RMS difference $\left(\mathrm{cm} \mathrm{s}^{-1}\right)$. All correlations are close to or above the $95 \%$ confidence level. The $95 \%$ confidential level of correlation coefficient is 0.40 for zonal velocity (with a decorrelation time scale of $\sim 4$ months) and 0.28 for meridional velocity (with a decorrelation time scale of $\sim 2$ months).

\begin{tabular}{lcccc}
\hline \hline & $\begin{array}{c}\text { Zonal AGC, } \\
\text { current meter }\end{array}$ & $\begin{array}{c}\text { Zonal altimeter, } \\
\text { current meter }\end{array}$ & $\begin{array}{c}\text { Meridional AGC, } \\
\text { current meter }\end{array}$ & $\begin{array}{c}\text { Meridional altimeter, } \\
\text { current meter }\end{array}$ \\
\hline $8^{\circ} \mathrm{N}, 137^{\circ} \mathrm{E}$ & $0.38(7.32)$ & $0.755(5.75)$ & $0.59(4.05)$ & $0.5593(4.55)$ \\
$8^{\circ} \mathrm{N}, 156^{\circ} \mathrm{E}$ & $0.66(5.27)$ & $0.79(6.49)$ & $0.28(3.17)$ & $0.35(5.21)$ \\
\hline
\end{tabular}



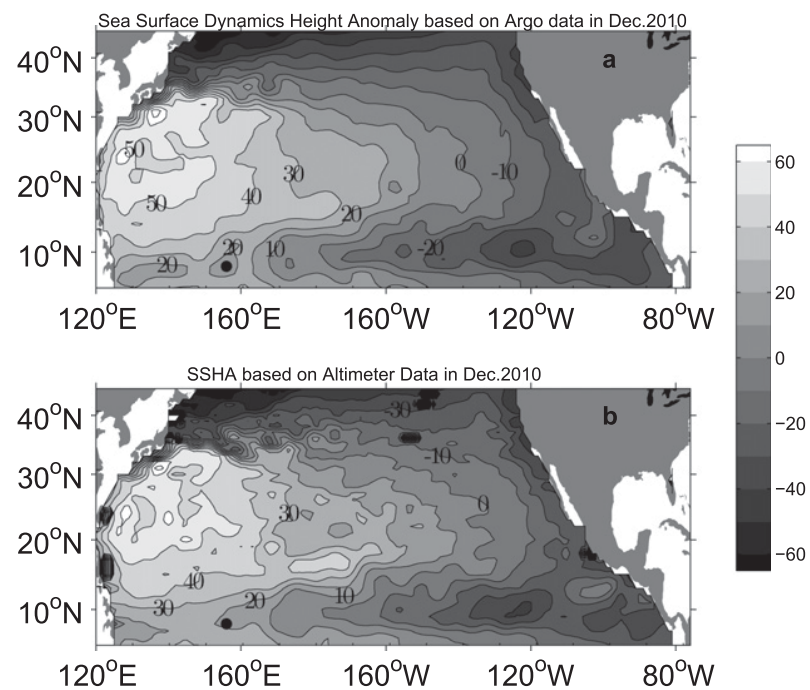

FIG. 3. Comparison of (a) the surface dynamic height $(\mathrm{cm})$ based on Argo profiles in reference to the $1900 \mathrm{~m}$ in December 2010 with (b) the sea surface height $(\mathrm{cm})$ of the satellite altimeter in December 2010, showing a dislocated eddy in the vicinity of the mooring site (marked with a dot) in the former. Spatial averages are removed from the plots. The contour interval is $10 \mathrm{~cm}$.

between the AGC and the current meter is 0.28 , in comparison with the correlation coefficient of 0.35 between the altimeter and current meter, both of which are above the $95 \%$ significance level. The low correlations are partly attributed to the short and intermittent currentmeter time series at this location. The RMS difference of the AGC meridional currents from the current-meter data is $3.17 \mathrm{~cm} \mathrm{~s}^{-1}$, much smaller than that of the altimeter meridional currents from the current-meter data of $5.21 \mathrm{~cm} \mathrm{~s}^{-1}$.

The distribution of the RMS differences of surface geostrophic currents between the AGC and the altimeter in the North Pacific Ocean is shown in Fig. 4 (top). Over the majority of the North Pacific Ocean, AGC are within a few centimeters per second from the altimeter geostrophic currents, except in the Kuroshio Extension area, where mesoscale eddies are active. The RMS differences are comparable with the estimated errors of the altimeter geostrophic currents (Rio and Hernandez 2004), suggesting the validity of AGC in studying the three-dimensional transport of the ocean. In particular, the RMS difference of the meridional geostrophic currents is small over the entire tropical North Pacific Ocean, suggesting that the data can be used to assess the accuracy of the Sverdrup theory.

The correlation coefficients of geostrophic current variations between the AGC and the altimeter are mostly between 0.3 and 0.6 for the meridional velocity, above the $95 \%$ significance level [Fig. 4 (bottom)]. The correlations for zonal velocity are mostly between around 0.3 and 0.9 in the western and tropical Pacific

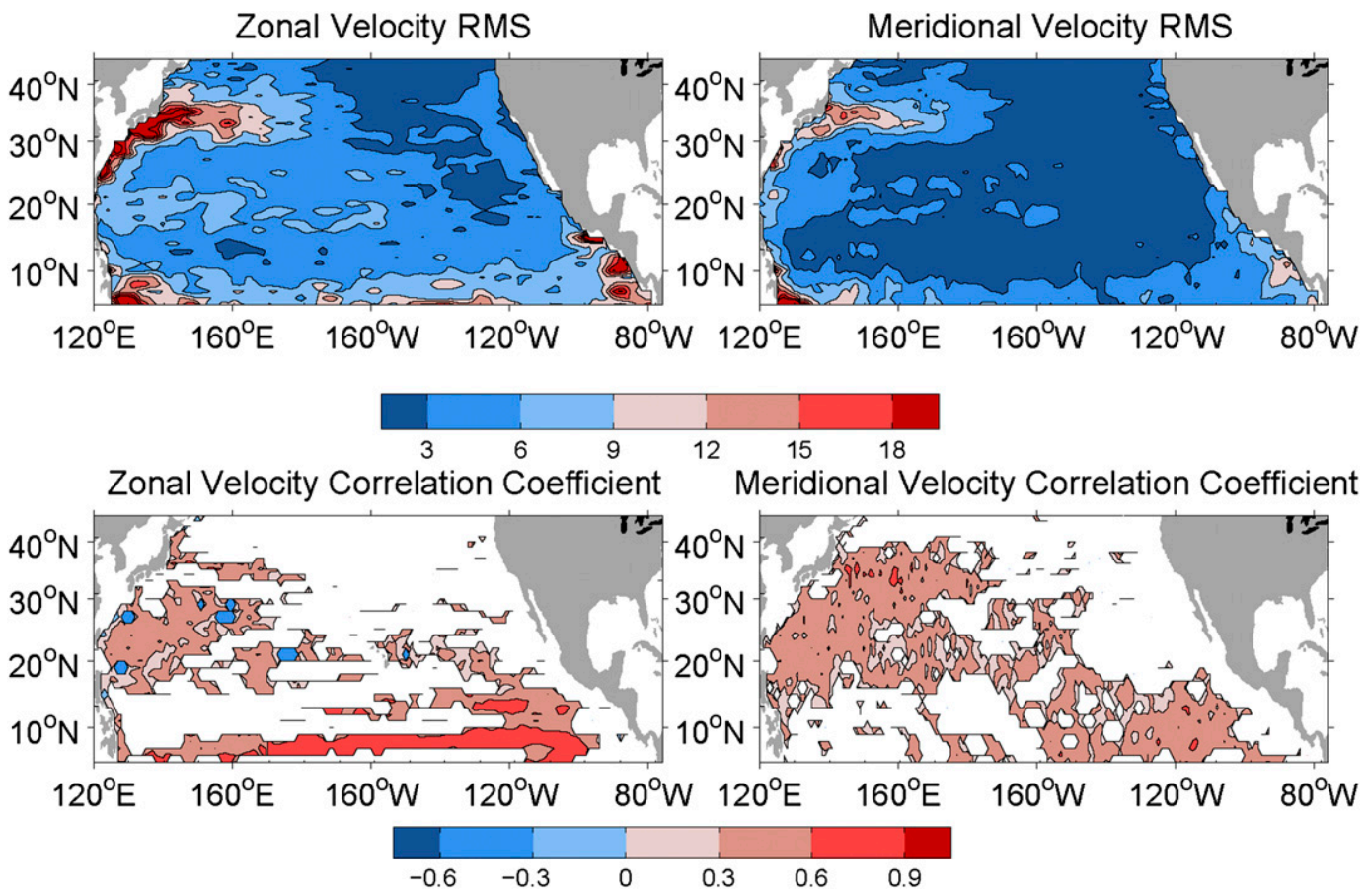

FIG. 4. RMS differences and correlation coefficients between the Argo AGC and altimeter geostrophic currents at the surface of the North Pacific Ocean during 2004-11. (top) RMS differences. Contour interval is $2 \mathrm{~cm} \mathrm{~s}^{-1}$. (bottom) Correlation coefficients (those below 95\% significance level are not shown). Contour interval is 0.2 . 

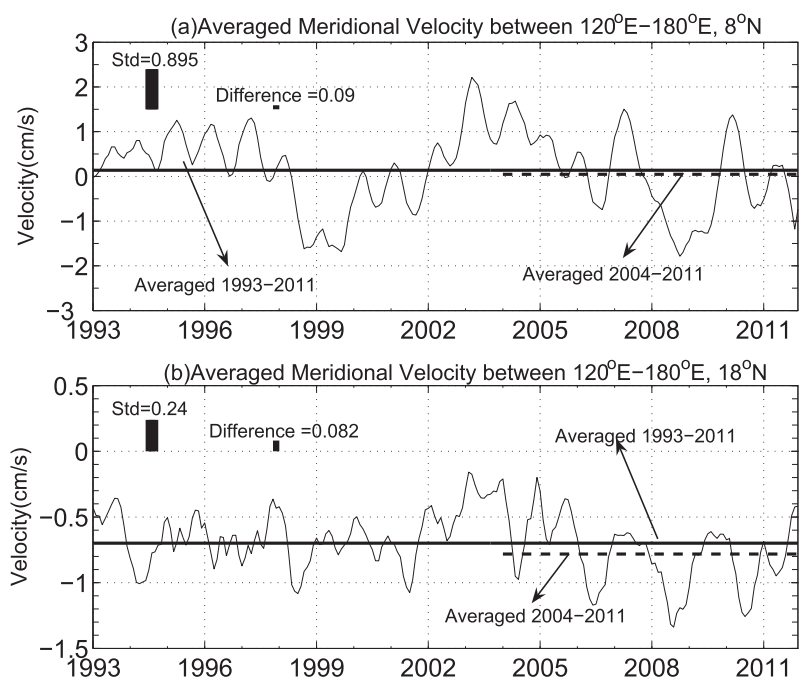

FIG. 5. Time series of area-averaged meridional geostrophic currents based on the satellite altimeter data between $120^{\circ} \mathrm{E}$ and the date line along (a) $8^{\circ} \mathrm{N}$ and (b) $18^{\circ} \mathrm{N}$. The short dashed and long solid lines represent the mean of 2004-11 and of 1993-2011, respectively. The std dev of 1993-2011 and the differences between the long- and short-term means are marked with the bars.

Ocean, also above the $95 \%$ significance level. Those in the eastern midlatitude Pacific are small and not as significant, mostly due to the sparse data coverage and longer decorrelation time scales, but that area is not the focus of this study. The above comparisons give us confidence that the P-vector AGC can be used to evaluate the Sverdrup balance and to study the three-dimensional transports of the North Pacific Ocean circulation.

\section{b. Comparison of AGC meridional transport with the Sverdrup theory}

The Sverdrup balance is examined using the AGC data. Because the Sverdrup theory is for steady-state circulation, the errors of the steady-state estimation based on the 8-year data are first examined using the altimeter geostrophic currents. Figures $5 \mathrm{a}$ and $5 \mathrm{~b}$ show the time series of the zonally averaged meridional velocity between $120^{\circ} \mathrm{E}$ and $180^{\circ}$ along $8^{\circ}$ and $18^{\circ} \mathrm{N}$, respectively, calculated from the altimeter sea level. The time means of 1993-2011 and of 2004-11 are plotted in thick solid and dashed lines for comparison. The 8-year averages are close to the 20-year averages compared with the standard deviation of the time series. But while the short-term mean at $8^{\circ} \mathrm{N}$ is within the $92 \%$ confidence interval of the long-term mean, at $18^{\circ} \mathrm{N}$ the short-term mean is merely within the $74 \%$ confidence interval of the long-term mean. Hence, the 8-year average at $8^{\circ} \mathrm{N}$ is a good approximation of the long-term mean circulation and can be used to validate the Sverdrup

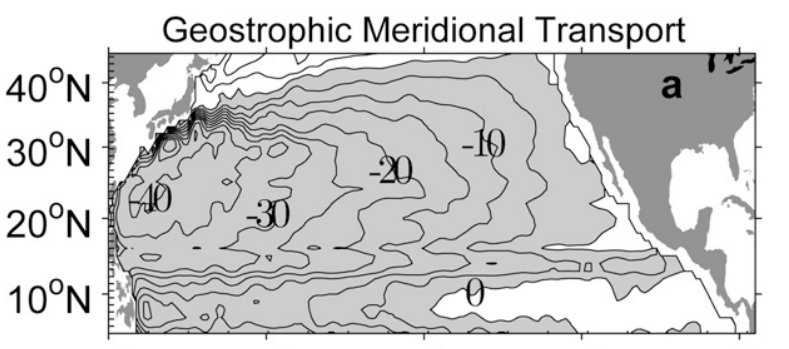

$120^{\circ} \mathrm{E} \quad 160^{\circ} \mathrm{E} \quad 160^{\circ} \mathrm{W} \quad 120^{\circ} \mathrm{W} \quad 80^{\circ} \mathrm{W}$ Meridional Sverdrup - Ekman Transport

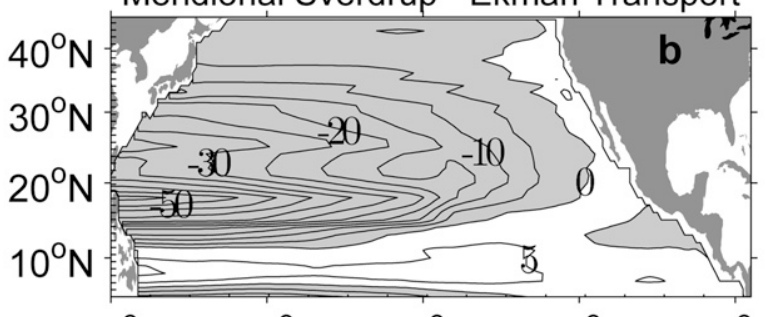

$120^{\circ} \mathrm{E} \quad 160^{\circ} \mathrm{E} \quad 160^{\circ} \mathrm{W} \quad 120^{\circ} \mathrm{W} \quad 80^{\circ} \mathrm{W}$ Difference between $a$ and $b$

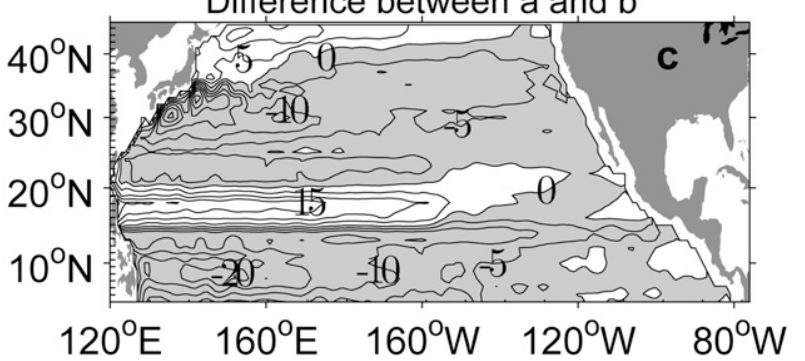

FIG. 6. Comparison of (a) 2004-11 mean meridional transport based on Argo AGC and the (b) $S-E$ transport based on the annual mean (2004-11) NCEP surface wind data in the North Pacific Ocean. (c) Their difference. Unit is $10^{6} \mathrm{~m}^{3} \mathrm{~s}^{-1}$. The wind stress calculation is based on the Garratt drag coefficient. The gray shading is negative.

theory, while at $18^{\circ} \mathrm{N}$ the 8 -year mean still contains sizable temporal variations.

The mean geostrophic meridional transport (Fig. 6a) and the $S-E$ meridional transport (Fig. 6b) in the North Pacific for the period of 2004-11 are calculated based on the left and right sides of Eq. (3). Here, the geostrophic meridional transport is integrated from $1900 \mathrm{~m}$ to the sea surface and from the eastern boundary of the North Pacific Ocean. The NCEP surface wind stress data based on the Garratt (1977) drag coefficient and averaged over 2004-11 were used to compute the $S-E$ transport. Subtracting the $S-E$ meridional transport from the geostrophic meridional transport yields the meridional transport discrepancy shown in Fig. 6c, which is the discrepancy from the Sverdrup theory. The $S-E$ transport is generally in good agreement with the geostrophic meridional transport in the eastern subtropical North Pacific Ocean and in 

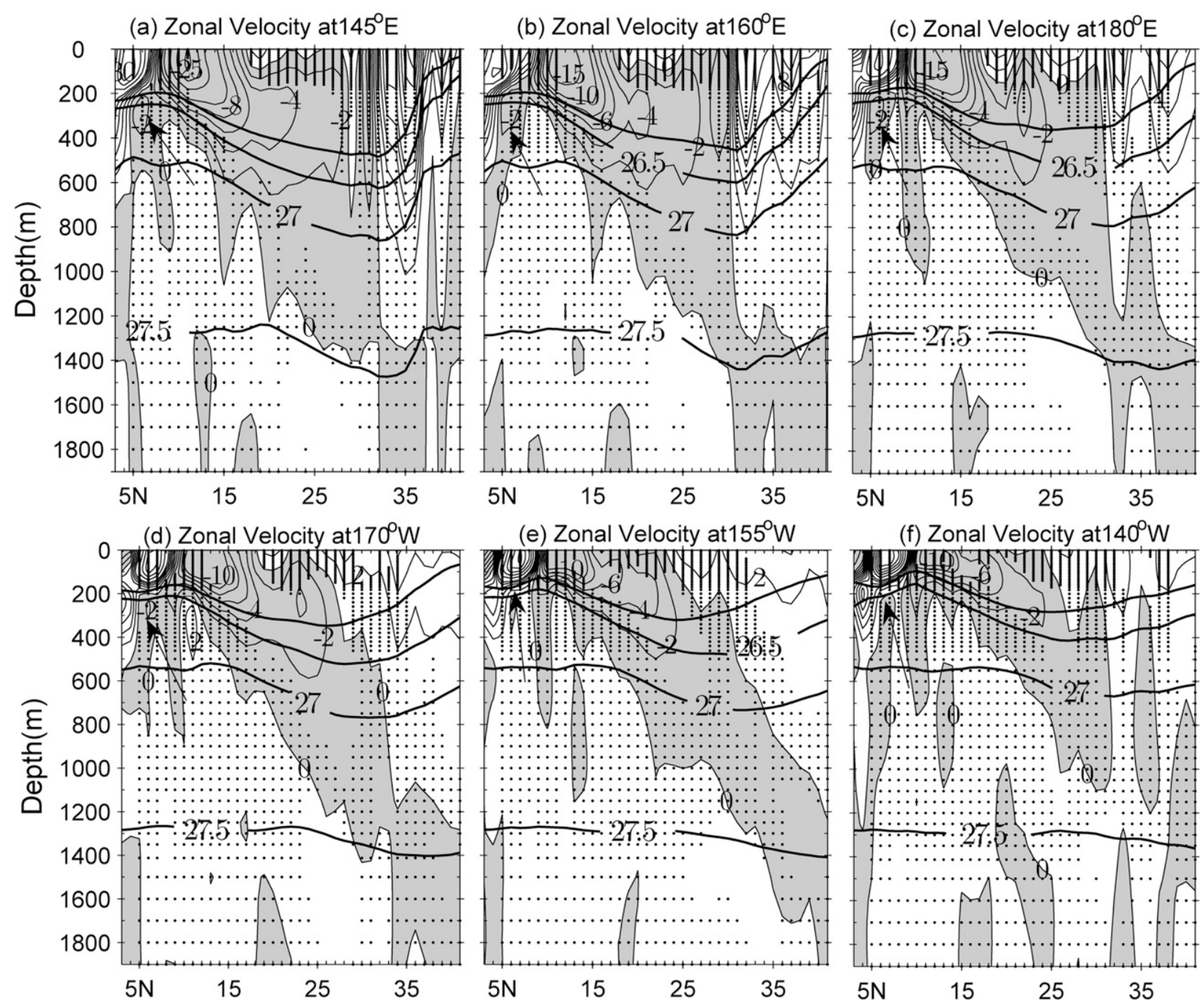

(e) Zonal Velocity at $155^{\circ} \mathrm{W}$

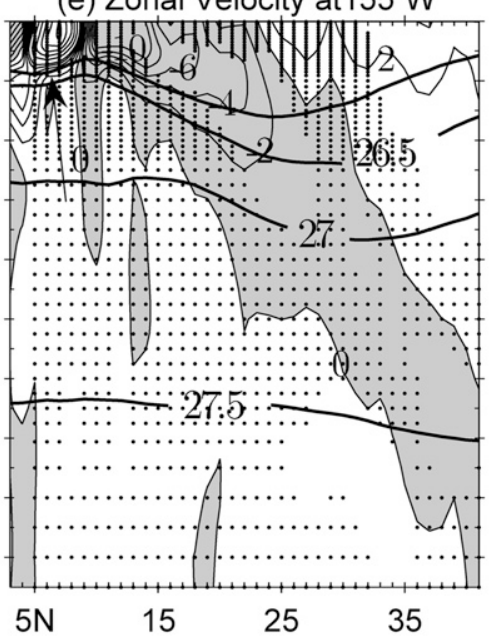

(f) Zonal Velocity at $140^{\circ} \mathrm{W}$

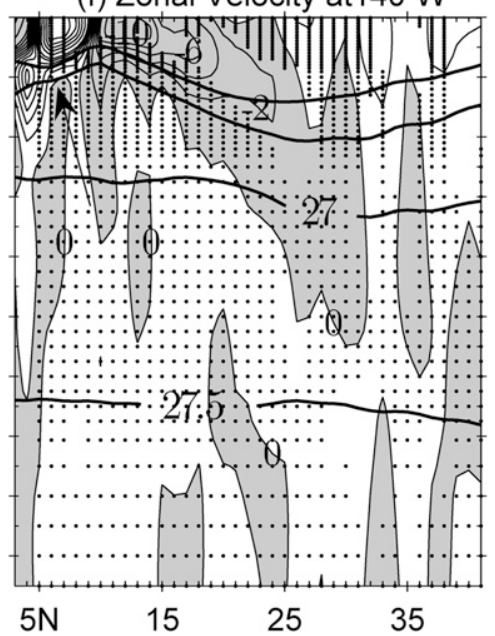

FIG. 7. The 2004-11 mean zonal geostrophic velocity (thin contours) from Argo data in different meridional sections across the North Pacific Ocean. Unit is $\mathrm{cm} \mathrm{s}^{-1}$. Thick contours mark the potential density surfaces. The contour interval is $2 \mathrm{~cm} \mathrm{~s}^{-1}$ for zonal velocity and $5 \mathrm{mg} \mathrm{cm}{ }^{-3}$ for potential density surfaces. The gray shading indicates westward currents. The dots at the grid points stand for signals below the error bars.

the area along roughly $15^{\circ}$ and $21^{\circ}-27^{\circ} \mathrm{N}$ west of the date line.

The agreement of the $S-E$ transport with the geostrophic meridional transport in the area between $21^{\circ}$ and $27^{\circ} \mathrm{N}$ is consistent with the analysis of Hautala et al. (1994) along $24^{\circ} \mathrm{N}$. The $S-E$ transport failed to explain the geostrophic meridional transport in the recirculation regions of the Kuroshio and its extension, perhaps owing to the deficiency of the linear approximation of the Sverdrup theory. Significant differences between the geostrophic meridional transport and the $S-E$ transport are also found in the region of $6^{\circ}-14^{\circ} \mathrm{N}$, $130^{\circ} \mathrm{E}-150^{\circ} \mathrm{W}$ between NEC and NECC and in the region of $15^{\circ}-20^{\circ} \mathrm{N}, 120^{\circ} \mathrm{E}-150^{\circ} \mathrm{W}$ between NEC and STCC as shown in Fig. 6c. The maximum differences are larger than 20 Sverdrups $\left(\mathrm{Sv} ; 1 \mathrm{~Sv} \equiv 10^{6} \mathrm{~m}^{3} \mathrm{~s}^{-1}\right)$, suggesting that the deviation of the circulation dynamics from the Sverdrup theory in these two areas is significant. In particular, the $S-E$ transport and the geostrophic meridional transport have opposite signs in the region between $6^{\circ}$ and $12^{\circ} \mathrm{N}$ in the western North Pacific Ocean, showing that the geostrophic currents there are not governed by the wind curl forcing at all.

\section{c. Three-dimensional structure of NEC}

The three-dimensional structure of the mean NEC in the North Pacific Ocean is examined using the P-vector AGC. Figure 7 shows the distribution of the mean zonal velocity in different meridional sections across the North Pacific Ocean. The signals smaller than the error bars are indicated by a dot at each point in the plots. The NEC transport is shown to increase toward the 
TABLE 2. Transports and std dev of major currents at different meridional sections in the North Pacific Ocean (Sv).

\begin{tabular}{|c|c|c|c|c|c|c|c|c|}
\hline Currents & Area of integration & $140^{\circ} \mathrm{E}$ & $145^{\circ} \mathrm{E}$ & $160^{\circ} \mathrm{E}$ & $180^{\circ}$ & $170^{\circ} \mathrm{W}$ & $155^{\circ} \mathrm{W}$ & $140^{\circ} \mathrm{W}$ \\
\hline NECC & $\begin{array}{l}3^{\circ}-7^{\circ} \mathrm{N}, \\
0-500 \mathrm{~m}, \\
u>0 \mathrm{~m} \mathrm{~s}^{-1}\end{array}$ & $23.4 \pm 8.3$ & $23.4 \pm 7.7$ & $17.7 \pm 6.3$ & $21.4 \pm 8.6$ & $20.4 \pm 8.3$ & $23.9 \pm 9.0$ & $23.4 \pm 7.2$ \\
\hline NESC & $\begin{array}{l}3^{\circ}-7^{\circ} \mathrm{N}, \\
200-600 \mathrm{~m}, \\
u<0 \mathrm{~m} \mathrm{~s}^{-1}\end{array}$ & $-4.2 \pm 1.2$ & $-3.8 \pm 1.0$ & $-3.7 \pm 0.9$ & $-3.5 \pm 0.9$ & $-3.2 \pm 0.9$ & $-2.5 \pm 0.7$ & $-3.3 \pm 09$ \\
\hline NEC & $\begin{array}{l}7^{\circ}-21^{\circ} \mathrm{N}, \\
0-120 \mathrm{~m}, \\
u<0 \mathrm{~m} \mathrm{~s}^{-1}\end{array}$ & $-61.9 \pm 6.0$ & $-56.8 \pm 4.7$ & $-47.2 \pm 4.7$ & $-37.1 \pm 4.3$ & $-30.5 \pm 3.6$ & $-29.5 \pm 4.5$ & $-21.1 \pm 4.2$ \\
\hline STCC & $\begin{array}{l}18^{\circ}-25^{\circ} \mathrm{N} \\
0-150 \mathrm{~m} \\
u>0\end{array}$ & $2.3 \pm 0.7$ & $2.0 \pm 0.9$ & $1.8 \pm 0.6$ & $2.3 \pm 0.7$ & $1.2 \pm 0.3$ & $1.3 \pm 0.4$ & $0.7 \pm 0.3$ \\
\hline KR & $\begin{array}{l}26^{\circ}-35^{\circ} \mathrm{N}, \\
0-1200 \mathrm{~m}, \\
u<0\end{array}$ & $-21 \pm 4.9$ & $-21.7 \pm 8.3$ & $-16.8 \pm 7.5$ & $-6.0 \pm 2.4$ & $-3.8 \pm 1.2$ & $-2.7 \pm 1.8$ & $-2.48 \pm 1.1$ \\
\hline $\mathrm{KE}$ & $\begin{array}{l}31^{\circ}-40^{\circ} \mathrm{N}, \\
0-1200 \mathrm{~m}, \\
u>0 \mathrm{~m} \mathrm{~s}^{-1}\end{array}$ & $46.0 \pm 6.3$ & $54.4 \pm 8.2$ & $41 \pm 8.0$ & $17.0 \pm 3.3$ & $12.1 \pm 1.3$ & $5.0 \pm 0.85$ & $3.5 \pm 1.0$ \\
\hline
\end{tabular}

western Pacific Ocean (Table 2). The axis (maximum zonal velocity) of the NEC is shown to shift to the north at depth. The $2 \mathrm{~cm} \mathrm{~s}^{-1}$ zonal velocity contours have shifted beneath the STCC and far north beyond at the 600-m depth, most of which are larger than the error bars. The maximum mean zonal velocity of the NEC exceeds $28 \mathrm{~cm} \mathrm{~s}^{-1}$ in the western Pacific Ocean.

South of the NEC at the surface, the NECC flows eastward above the 200-m depth. Underneath the NECC is a weak westward flow originating from the eastern Pacific Ocean with increasing zonal velocity toward the western Pacific Ocean. This current has not been named or discussed in the published literature. We have examined historical data and found that this current was indeed indicated by direct ADCP measurements at $5^{\circ} \mathrm{N}, 142^{\circ} \mathrm{E}$ on 22 December 2001 and at $5^{\circ} \mathrm{N}, 137^{\circ} \mathrm{E}$ on 27 October 2002 archived by Japan Oceanographic Data Center (Fig. 8). This current is evident in almost all of the monthly-mean AGC maps with a velocity core separate from the NEC. Historically, mean current maps are difficult to obtain in the low latitudes due to contamination by the strong intraseasonal signals. The basin-scale, high-frequency, and synchronous mapping of the Pacific Ocean by Argo profiling floats allow us to determine the mean currents with some confidence. We shall call this current the North Equatorial Subsurface Current (NESC) in the following text. The maximum mean velocity of the NESC exceeds $2 \mathrm{~cm} \mathrm{~s}^{-1}$ in the western North Pacific Ocean according to the AGC calculation and the ADCP measurements. The westward transport of the NESC between $3^{\circ}$ and $7^{\circ} \mathrm{N}$ and at the depth range of $200-600 \mathrm{~m}$ at $140^{\circ} \mathrm{E}$ is as large as $4.2 \mathrm{~Sv}$ (Table 2). However, both the NESC and the western Pacific part of the NECC are within the error bars, due to the strong eddy activities there.

The northwestern Pacific Ocean has rich subsurface undercurrents, none of which have dynamical explanations so far. Recently, Cravatte et al. (2012) have observed alternating zonal currents at the intermediate depths of 1000 and $1500 \mathrm{~m}$. Qiu et al. (2013a) suggested that these currents are generated by a nonlinear triad instability of the Rossby waves radiated from the eastern boundary. The theory did not explain stronger zonal currents in the western Pacific Ocean than in the east. Further studies are needed to understand the dynamics.

North of the NEC at the surface is a weak eastward current called the STCC. Farther north of it is the Kuroshio recirculation (KR) flowing to the west. These currents are within the error bars due to the strong eddy activity. The strong Kuroshio and its extension, although below the measurement errors, are easily identified in the sectional distribution of the zonal currents north of about $30^{\circ} \mathrm{N}$. The Kuroshio Extension east of $160^{\circ} \mathrm{E}$ has double cores in the mean field, perhaps owing to an effect of the Shatsky Rise located at about $158^{\circ} \mathrm{E}$.

Directly underneath the NEC, the mean flow is extremely weak and within the error bars. The P-vector calculation has not identified any mean eastward-flowing undercurrent core beneath NEC east of $145^{\circ} \mathrm{E}$ across the Pacific basin.

A comparison of the Argo AGC and the WOA09 AGC suggests that the zonal patterns of the two sets of AGC are similar overall (Fig. 9). The WOA09 fields have been smoothed in space to eliminate subgrid-scale structure. The AGC based on the WOA09 hydrography data have underestimated the strength of the NESC 

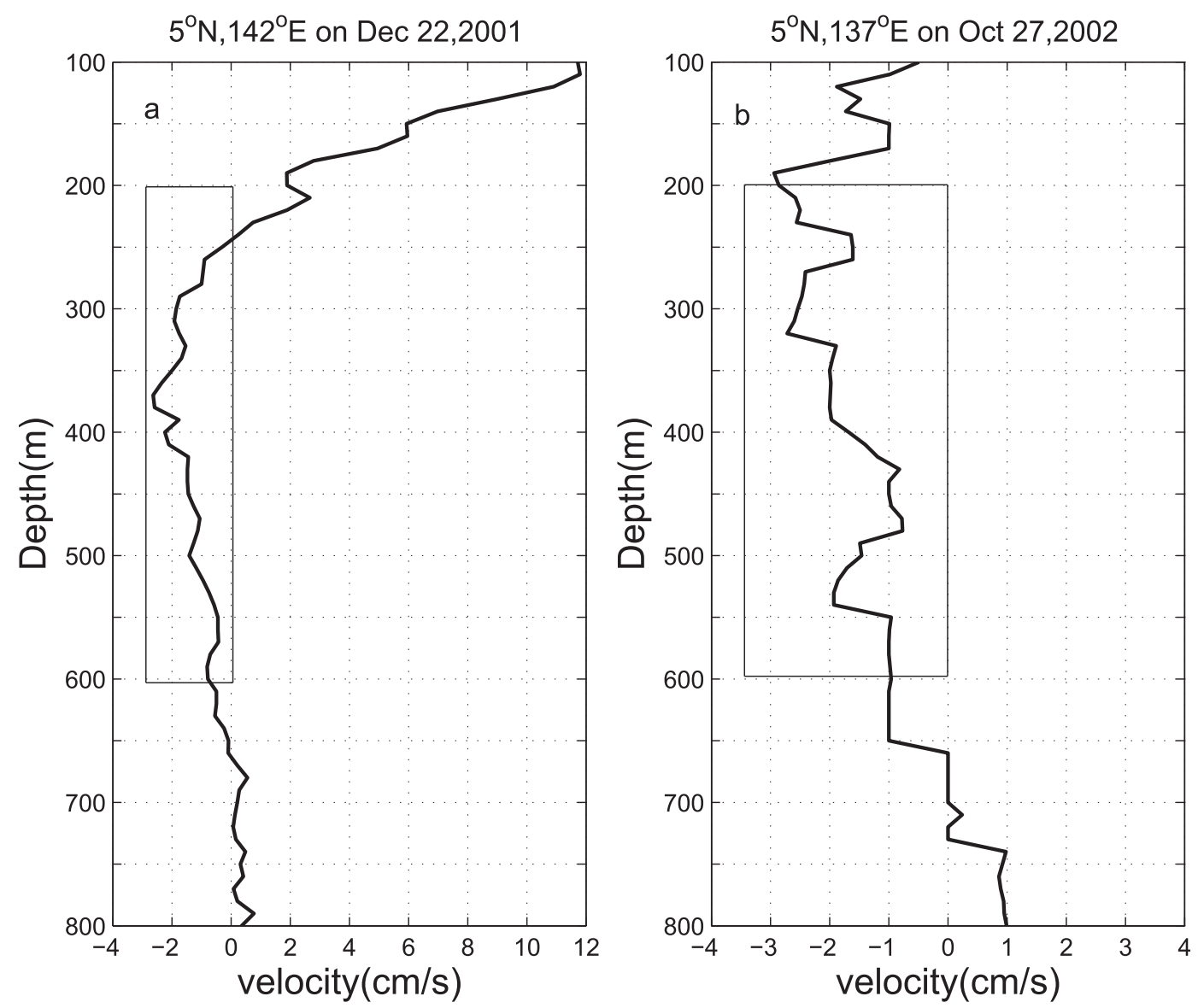

FIG. 8. In situ zonal velocity profiles measured by ADCP current meters (a) at $5^{\circ} \mathrm{N}, 142^{\circ} \mathrm{E}$ on $22 \mathrm{Dec} 2001$ and (b) at $5^{\circ} \mathrm{N}, 137^{\circ} \mathrm{E}$ on 27 Oct 2002.

beneath the NECC in the subsurface northwestern Pacific Ocean significantly. The difference explains why the NESC was not discussed by previous studies using synoptic surveys of the regional hydrography. In comparison, the Argo profiles show the existence of the NESC clearly. The NESC weakens in the Philippine Sea as it approaches the western boundary and eventually merges with the New Guinea Coastal Undercurrent at about $128^{\circ} \mathrm{E}$ according to the Argo AGC (figure omitted).

The strength of the NEC and the NECC increases westward in the Philippine Sea (Fig. 9), the magnitudes of which in the northwestern Pacific Ocean are also significantly underestimated by WOA09 data due to the smoothing. Two eastward undercurrent cores are identified underneath the westward-flowing NEC in the Philippine Sea in the Argo AGC, which are called the North Equatorial Undercurrent by $\mathrm{Hu}$ et al. (1991) and by Qiu et al. (2013b). The Argo data suggest that the North Equatorial Undercurrent is confined in the Philippine Sea west of about $140^{\circ} E$. None of the undercurrent cores are identified in the AGC inverted from the WOA09 data.
The combination of Eqs. (1c) and (2) yields the zonal wind-driven Sverdrup transport. Following the convention used in this paper, the vertically integrated zonal transport is calculated from the AGC and is compared with the $S-E$ zonal transport based on the Sverdrup theory (Fig. 10). Figures 10a and 10b show that the AGC and the Sverdrup zonal transports are significantly different from each other. The differences of the AGC from the $S-E$ zonal transport are primarily in the same zonal bands as are the largest meridional transport differences in the tropical northwestern Pacific Ocean in Fig. $6 \mathrm{c}$. The comparisons suggest that the difference of the AGC transports from the Sverdrup theory is structural, which indicates a deficiency of the classical Sverdrup theory in estimating the zonal and meridional transports of the tropical North Pacific Ocean circulation.

\section{Discussions}

\section{a. Error estimates}

We have estimated the errors of the geostrophic currents based on the standard deviation of the density 

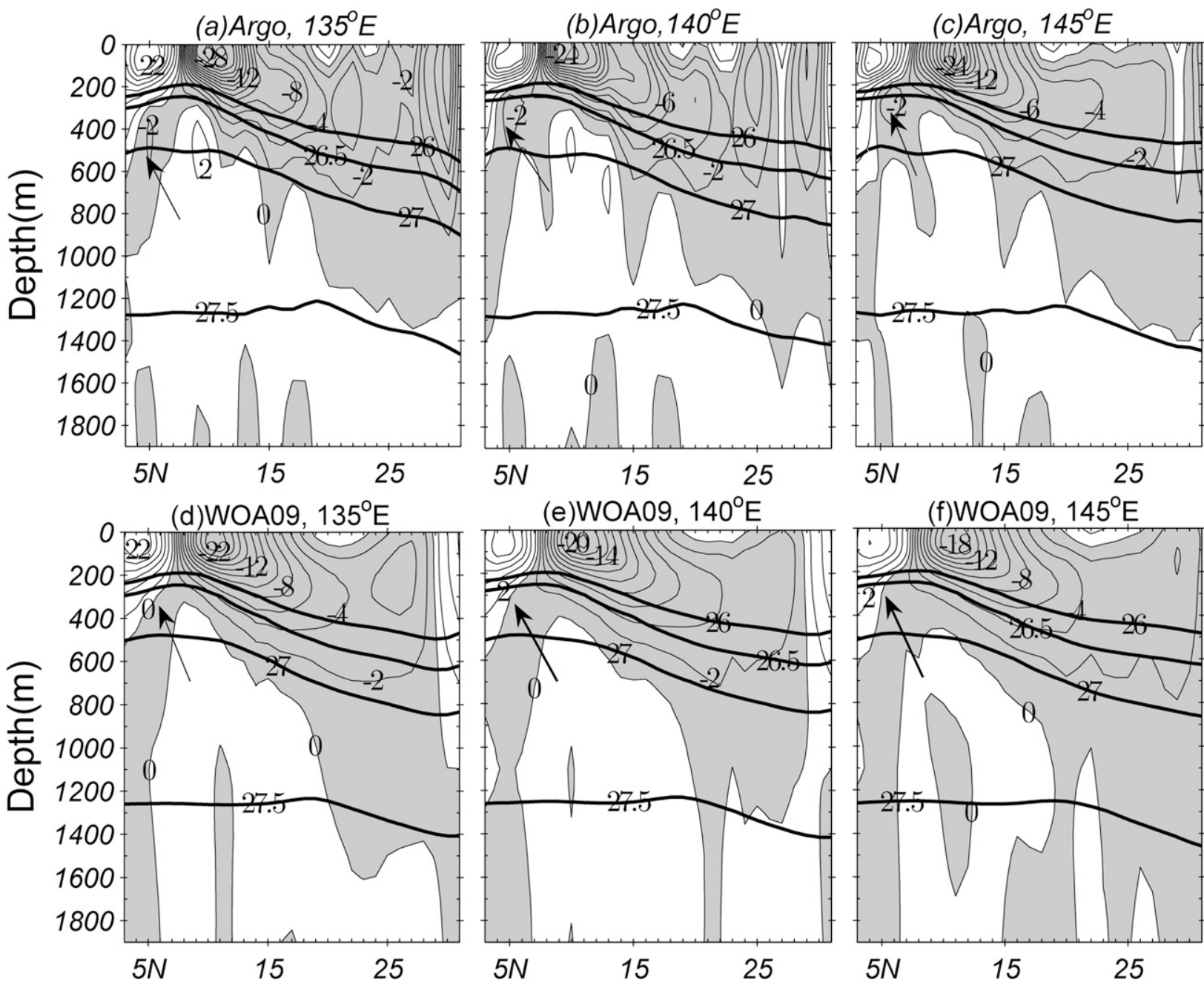

FIG. 9. Comparison of the AGC based on the (a)-(c) Argo and the (d)-(f) WOAO9 hydrography data at different meridional sections across the tropical northwestern Pacific Ocean. Contour interval is $2 \mathrm{~cm} \mathrm{~s}^{-1}$. Thick contours mark the potential density surfaces. The gray shading indicates westward currents.

fields in combination with the thermal wind relation. The error of the least squares fitting between 800 and $1900 \mathrm{~m}$ is believed to be smaller than this estimate. Thus, our error estimate represents the upper bound of the geostrophic current errors induced by the density errors. In addition, the standard deviations of the AGC time series are used to estimate the errors induced by the time dependency of the currents. One standard deviation is taken into consideration of the error estimate. Figure 11 shows the errors of the surface zonal and meridional AGC and of the meridional transport of the AGC based on the above estimates. The error bars of the AGC are comparable with those of the altimeter geostrophic currents of a few centimeters per second according to Rio and Hernandez (2004). The error bars for the meridional transport are generally smaller than $2 \mathrm{~Sv}$, except near the western boundary and in the
Kuroshio Extension. The small magnitudes of the error bars in comparison with the structural differences from the Sverdrup relation suggest that the identified differences of the AGC meridional transports from the $S-E$ meridional transport are statistically significant.

\section{b. Geostrophic meridional transport discrepancy based on the WOA data}

The above analyses suggest that the geostrophic transports in the upper ocean differ significantly from the simple linear Sverdrup relation in some areas of the tropical North Pacific. It is important to know if these differences are specific for the Argo profile data. For this purpose, we compare the meridional transport of the WOA09 AGC with the $S-E$ transport in Fig. 12 . The calculation of the transports in Fig. 12 is exactly the same as in Fig. 6, except using the WOAO9 data. The 
Geostrophic zonal Transport $\left(\mathrm{m}^{2} / \mathrm{s}\right)$

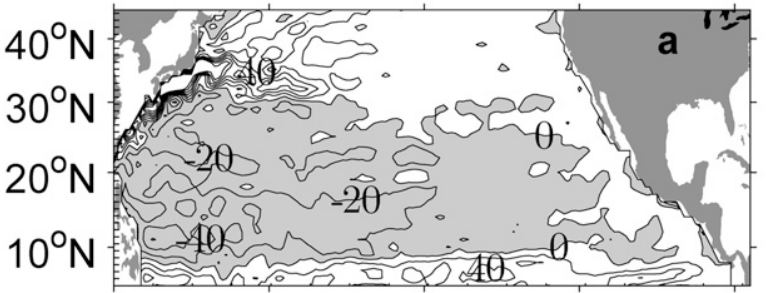

$120^{\circ} \mathrm{E} \quad 160^{\circ} \mathrm{E} \quad 160^{\circ} \mathrm{W} \quad 120^{\circ} \mathrm{W} \quad 80^{\circ} \mathrm{W}$ Zonal Sverdrup - Ekman Transport

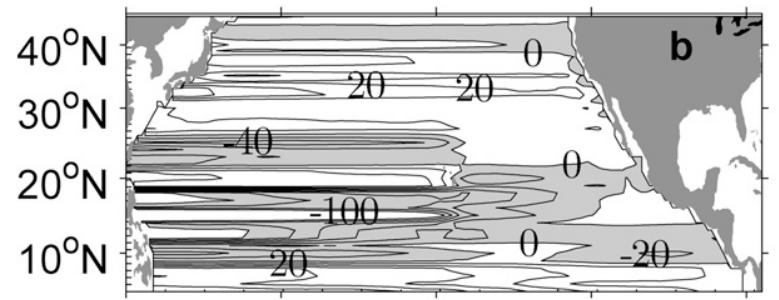

$120^{\circ} \mathrm{E} \quad 160^{\circ} \mathrm{E} \quad 160^{\circ} \mathrm{W} \quad 120^{\circ} \mathrm{W} \quad 80^{\circ} \mathrm{W}$ Difference between $a$ and $b$

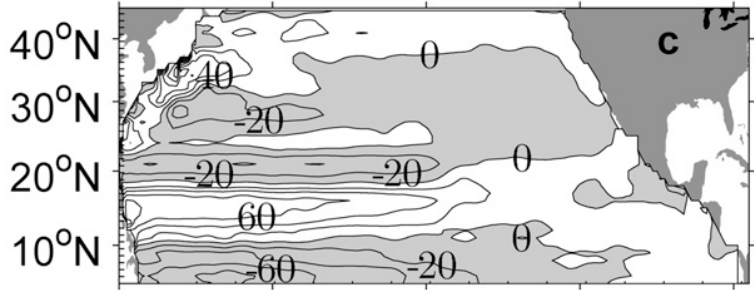

$120^{\circ} \mathrm{E} \quad 160^{\circ} \mathrm{E} \quad 160^{\circ} \mathrm{W} \quad 120^{\circ} \mathrm{W} \quad 80^{\circ} \mathrm{W}$

FIG. 10. (a),(b) Mean vertically integrated zonal transport of the AGC and of the Sverdrup theory and (c) their difference. Unit is $\mathrm{m}^{2} \mathrm{~s}^{-1}$. The gray shading indicates westward currents.

meridional transport of the geostrophic currents and its deviation from the $S-E$ transport are almost identical to those based on the Argo profiles, suggesting that the deviation of the geostrophic transport from the linear Sverdrup theory is robust.

\section{c. Independence of the meridional transport discrepancy on depth $H$}

The Sverdrup relation in Eq. (2) is established with the assumption of zero vertical velocity at the depth $z=-H$. We have conducted sensitivity tests and found that the meridional transport discrepancy in Fig. $6 \mathrm{c}$ is not sensitive to the selection of $H$ below, say, $1500 \mathrm{~m}$ (figures omitted). Modern discussions of the Sverdrup theory have suggested that the assumption of zero vertical velocity at a constant depth $H$ is one of the primary restrictions of the theory (Marchuk et al. 1973; Wunsch and Roemmich 1985). However, the vertical integration of the continuity equation over a varying

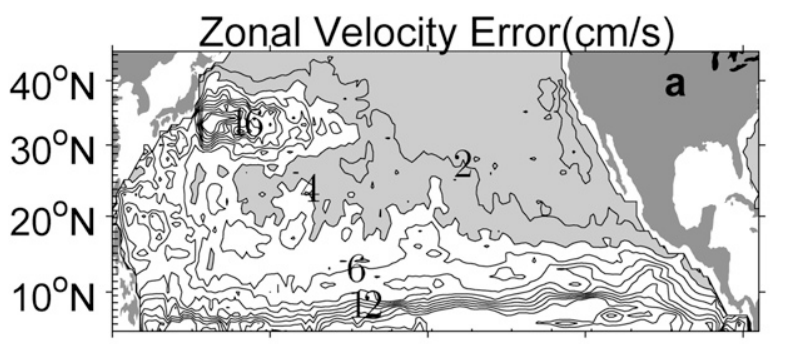

$120^{\circ} \mathrm{E} \quad 160^{\circ} \mathrm{E} \quad 160^{\circ} \mathrm{W} \quad 120^{\circ} \mathrm{W} \quad 80^{\circ} \mathrm{W}$ Meridional Velocity Error $(\mathrm{cm} / \mathrm{s})$

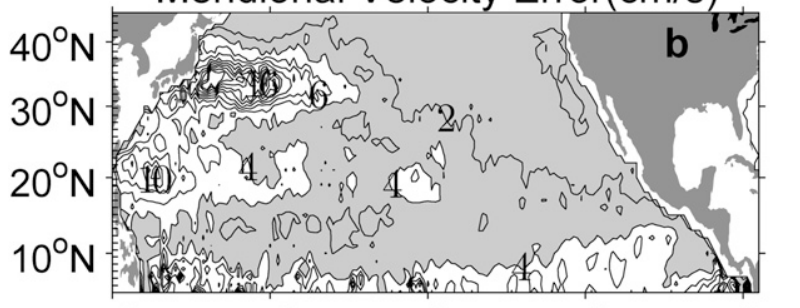

$120^{\circ} \mathrm{E} \quad 160^{\circ} \mathrm{E} \quad 160^{\circ} \mathrm{W} \quad 120^{\circ} \mathrm{W} \quad 80^{\circ} \mathrm{W}$ Meridional Transport Error(Sv)

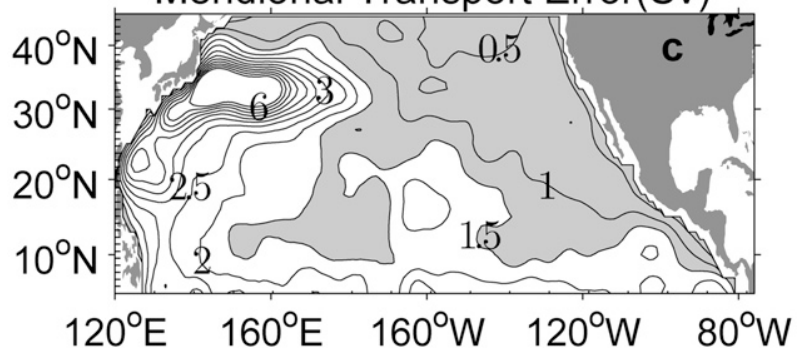

FIG. 11. Error bars (see text) of the (a) surface zonal and (b) meridional geostrophic currents based on Argo data and (c) of the grid meridional transport of the geostrophic currents smoothed by a $5^{\circ}$ lon by $5^{\circ}$ lat average filter. Contour intervals are $2 \mathrm{~cm} \mathrm{~s}^{-1}$ for the surface AGC and $0.5 \mathrm{~Sv}$ for the meridional transport. The gray shading indicates less than $4 \mathrm{~cm} \mathrm{~s}^{-1}$ for (a) and (b) and $1.5 \mathrm{~Sv}$ for (c).

depth $z=-H(x, y)$ will result in extra terms in Eq. (3), which will destroy the elegance of the Sverdrup relation in Eq. (2). An exception is if $z=-H(x, y)$ is a isopycnal surface. However, the cross-differentiation of the momentum equations will generate a joint baroclinicity and relief (JBAR) term in the Sverdrup relation (Marchuk et al. 1973). Assuming the JBAR term is small due to the flat isopycnals in the abyssal tropical oceans (e.g., Figs. 7 and 9), one can test the accuracy of the Sverdrup relation based on vertical integrations above different isopycnal surfaces.

The meridional transport differences between the left and right sides of Eq. (3) based on different values of $H$ corresponding to $\sigma_{\theta}$ levels of 26.5, 27.0, 27.2, and 27.5 for the left side of Eq. (3) are shown in Fig. 13. The overall meridional transport discrepancies from the Sverdrup theory for different $\sigma_{\theta}$ levels are similar to 

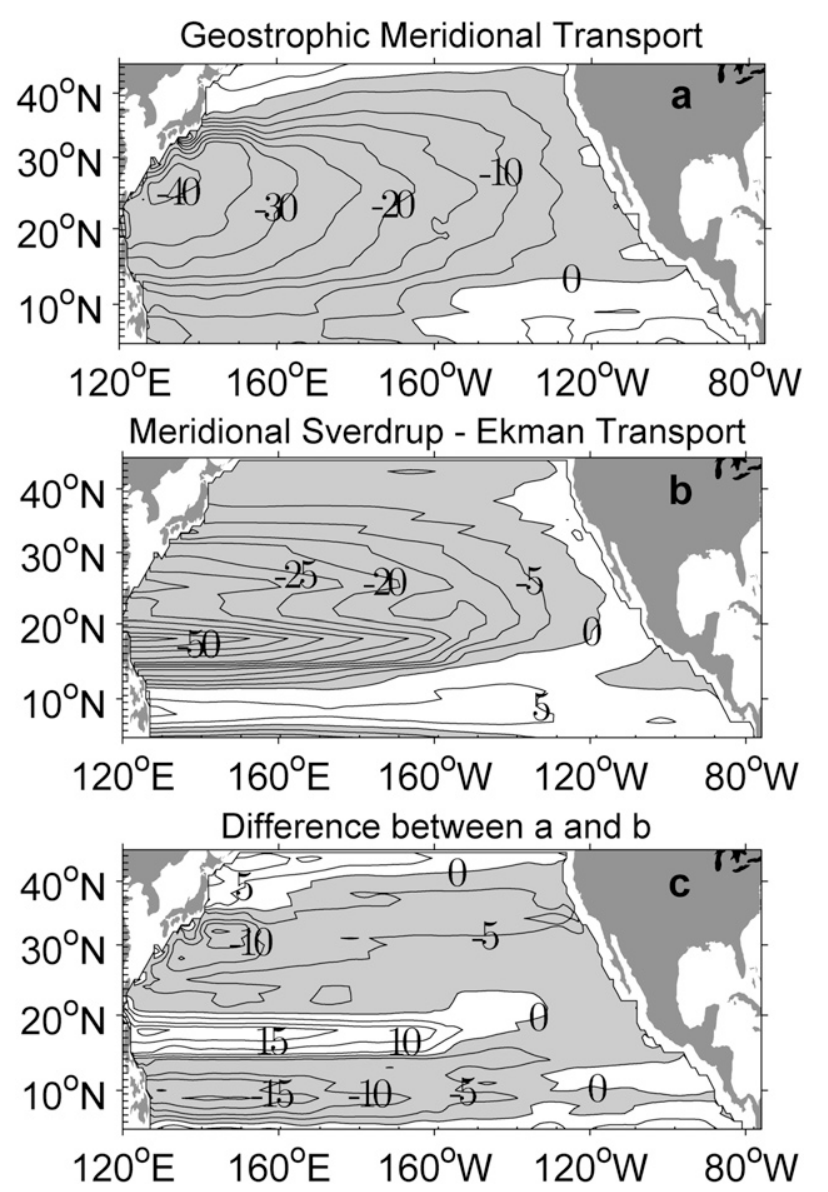

FIG. 12. As in Fig. 6, but for AGC meridional transport based on WOA09 data. Unit is $10^{6} \mathrm{~m}^{3} \mathrm{~s}^{-1}$. The bottom limit of the vertical integration is $1900 \mathrm{~m}$. The gray shade is negative.

those in Fig. 6c and much larger than the error bar estimates in the areas of $6^{\circ}-12^{\circ} \mathrm{N}$ and $15^{\circ}-20^{\circ} \mathrm{N}$, suggesting their significance and independence of the bottom limit of the vertical integration.

\section{d. Independence of meridional transport discrepancy on surface wind data}

To further understand the reason for the large differences of the geostrophic meridional transport from the Sverdrup linear theory in the areas of $6^{\circ}-12^{\circ} \mathrm{N}$ and $15^{\circ}-20^{\circ} \mathrm{N}$ of the western North Pacific, averaged ERA-40 surface wind stress data for the period of 1961-2000 and averaged NCEP-NCAR reanalysis surface wind stress data for the period of 1948-2011 are used to examine the sensitivity of the meridional transport discrepancy on the surface wind products. These surface wind stress products are calculated using the drag coefficient of Large and Pond (1981).

The differences between the left and the right sides of Eq. (3) for different wind products are shown in Figs. 14a and $14 \mathrm{~b}$. For these experiments, the lower limit of the vertical integration of the geostrophic meridional transport is set at $\sigma_{\theta}=27.2$. The spatial patterns of the deviation from the Sverdrup theory in Figs. 14a and 14b for the different wind products are similar to those in Fig. 6c, with the maximum differences larger than 20 Sv, suggesting that the deviation from the Sverdrup theory in these two areas is robust. These results also suggest that the wind stress errors cannot account for all of the meridional transport discrepancies from the Sverdrup theory.

\section{e. Independence of meridional transport discrepancy on drag coefficients}

The Large and Pond formula suggests that the drag coefficient used to calculate the wind stress increases with wind speed. Recent studies indicate that the drag coefficient in the marine atmospheric boundary layer increases with the wind speed for moderate winds and levels out at high wind speed (Foreman and Emeis 2010). The use of the Foreman and Emeis drag coefficients has resulted in a similar pattern of the geostrophic meridional transport discrepancies from the $S-E$ transport as in Fig. 6c (Fig. 14d). The magnitudes of the meridional transport discrepancies using the Foreman and Emeis drag coefficients in Fig. 14d are about 5 Sv larger than those using the Large and Pond drag coefficients shown in Fig. 14c, suggesting that the uncertainty of the drag coefficients is not the main reason for the geostrophic meridional transport discrepancies from the $S-E$ transport.

\section{f. The Sverdrup balance in a high-resolution ocean model}

The high-resolution OFES provides an opportunity to investigate the origin of the meridional transport discrepancy in the interior tropical and subtropical northwestern Pacific Ocean. Here, the climatological annual-mean NCEP wind stress used to drive the model is used to calculate the $S-E$ transport. The geostrophic meridional transport is calculated from the OFES climatological annual-mean temperature and salinity simulations using the P-vector method. The lower bound of the vertical integration $H$ is chosen to be $1900 \mathrm{~m}$. Experiments using different isopycnic surfaces $\left(\sigma_{\theta}\right.$ such as $26.5,27.0,27.2$, and 27.5) as the lower bound of the vertical integration of the geostrophic meridional transport calculation show essentially the same results (not shown). Figure 15a shows the significant meridional transport discrepancy in the latitudinal bands of $6^{\circ}-12^{\circ} \mathrm{N}$ and $12^{\circ}-20^{\circ} \mathrm{N}$, the magnitude and area coverage being essentially the same as those based on the Argo data (as shown in Fig. 6c). The maximum differences are $\sim 5 \mathrm{~Sv}$ in 

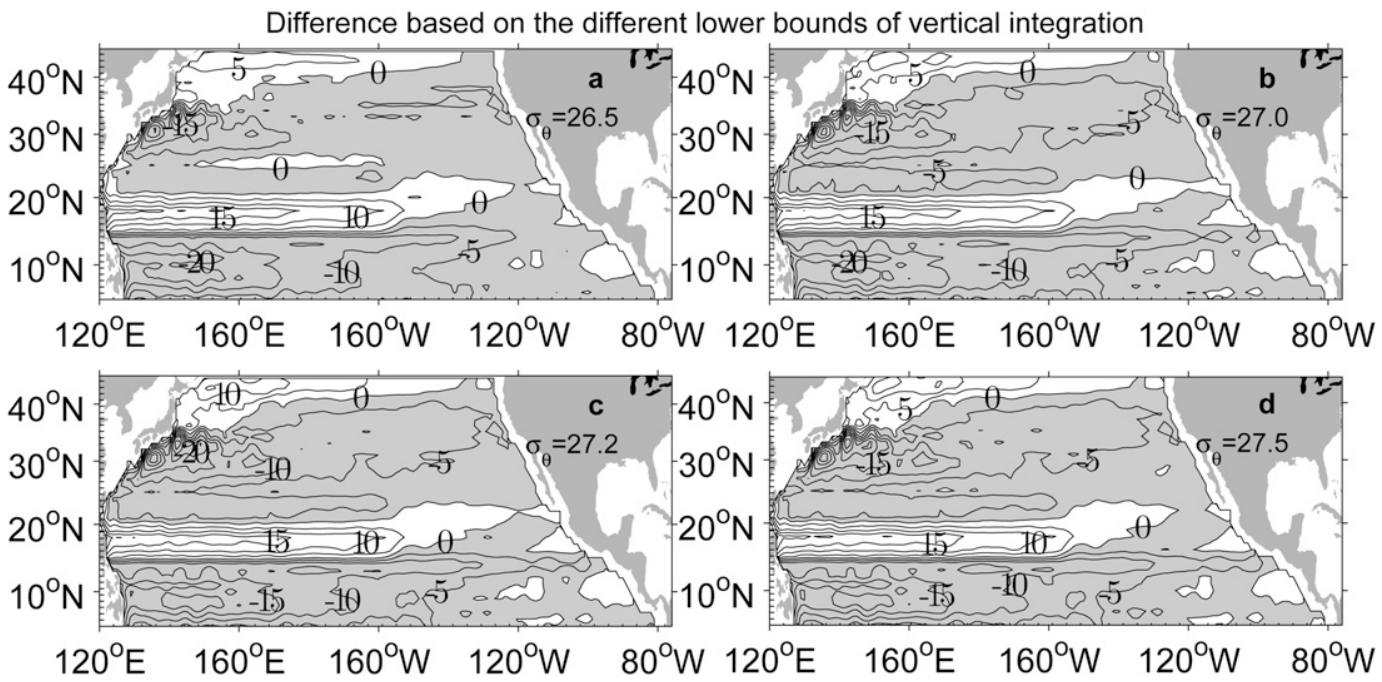

FIG. 13. Dependence of the meridional transport discrepancy on the choice of the isopycnal surfaces $\left(\sigma_{\theta}\right.$ levels) (a) 26.5, (b) 27.0, (c) 27.2, and (d) 27.5, respectively, as the bottom limits of the integration. The geostrophic transport is based on the Argo geostrophic currents. The Sverdrup balance is based on the NCEP wind. The gray area is negative. Contour interval is $5 \mathrm{~Sv}$.

$6^{\circ}-12^{\circ} \mathrm{N}$ and more than $10 \mathrm{~Sv}$ in $12^{\circ}-20^{\circ} \mathrm{N}$. Because the OFES simulation is dynamically consistent with the wind forcing, it should satisfy the Sverdrup balance exactly, should the dynamics be linear. The above comparison suggests strongly that the significant meridional transport discrepancy is due to nonlinear effects within OFES.

An alternative method of calculating the ocean meridional transport is to use the OFES-simulated velocity, which includes geostrophic and ageostrophic components. The Sverdrup transport, that is, the first term on the right side of Eq. (3), is subtracted from the simulated meridional transport. The difference is shown in Fig. 15b. The meridional transport discrepancy of the model is essentially the same as that of the AGC (Fig. 15a) in the interior tropical northwestern Pacific Ocean, which suggests that the Sverdrup relation is not a valid approximation of the leading-order general ocean circulation in the North Pacific Ocean.
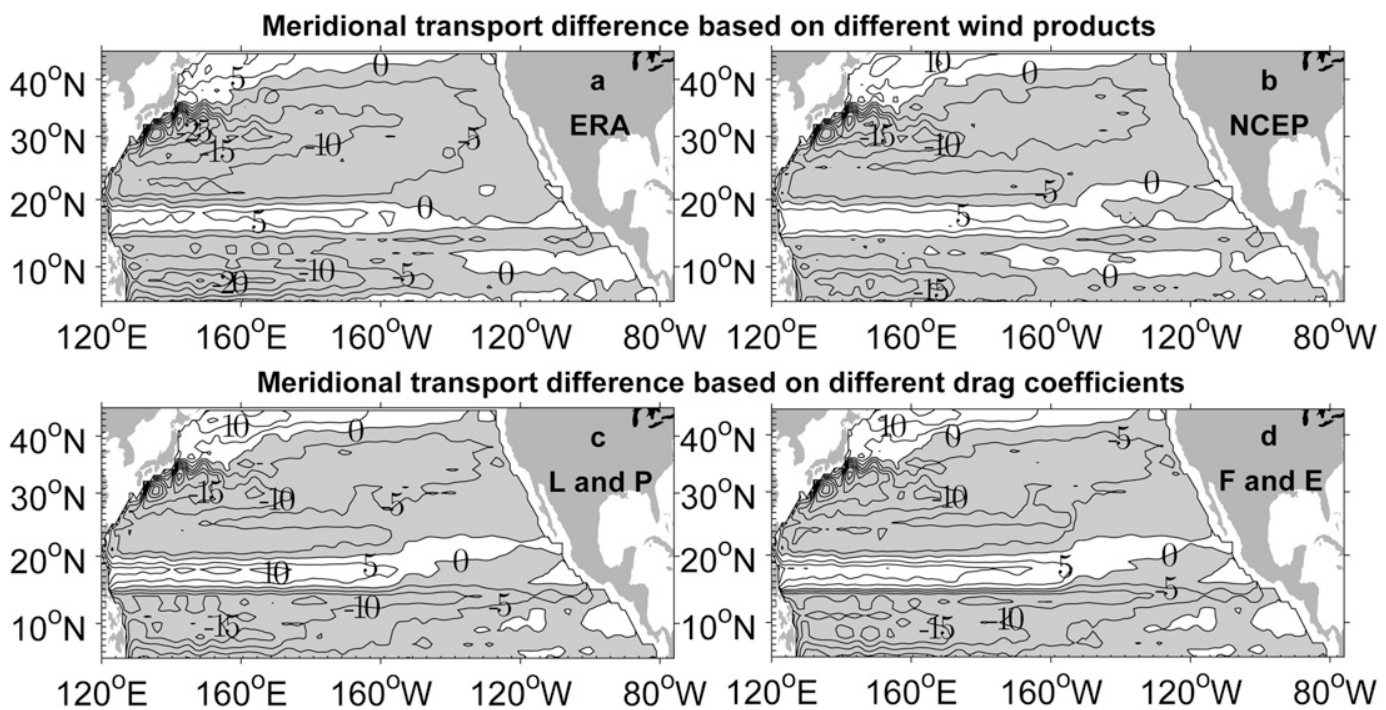

FIG. 14. Meridional transport discrepancy based on (a) ERA-40 surface mean (1961-2000) wind stress, (b) NCEP surface mean (1948-2011) wind stress, (c) NCEP surface mean (2004-11) wind vector using the Large and Pond (1981) drag coefficients, and (d) NCEP surface mean (2004-11) wind vector using the Foreman and Emeis (2010) drag coefficients. The gray shade is negative. 

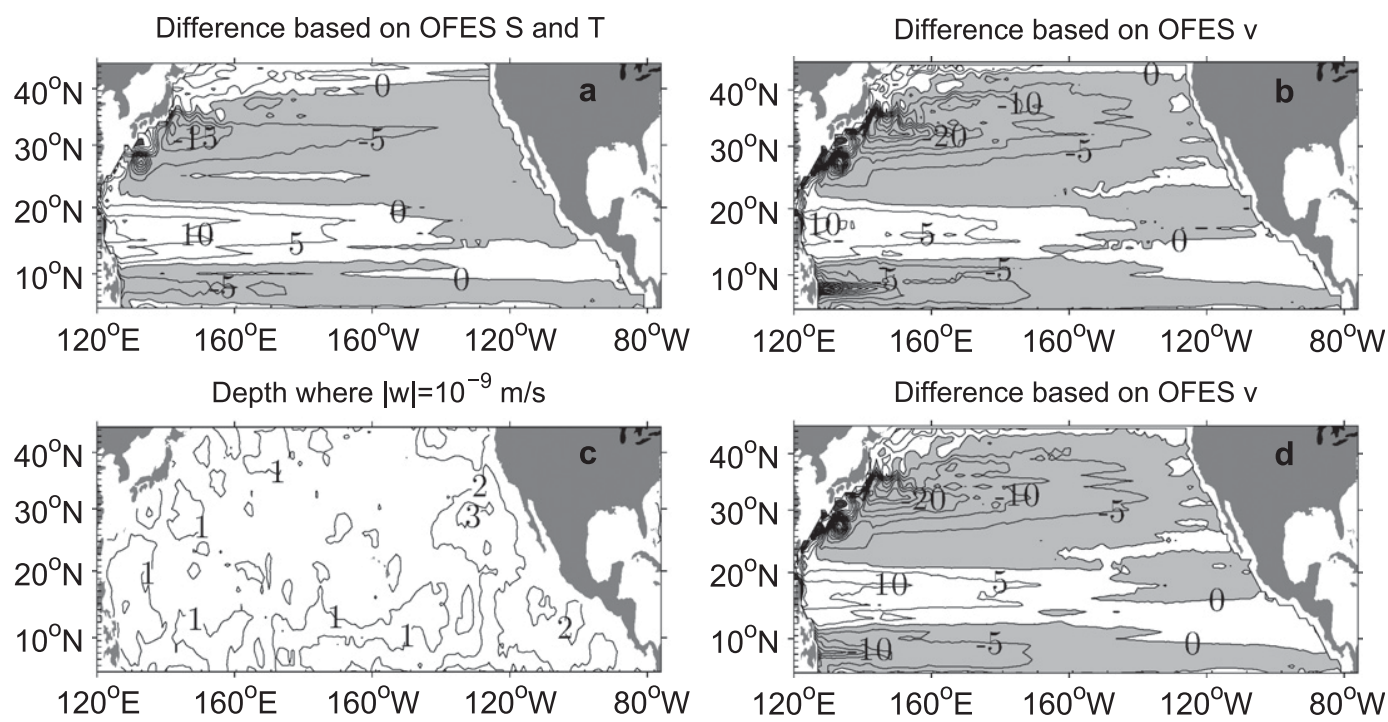

FIG. 15. Comparison of the meridional transport discrepancies of OFES from the wind-driven meridional transport based on Sverdrup balance. (a) The OFES meridional transport is calculated based on the geostrophic currents calculated from the OFES-simulated temperature and salinity fields using the P-vector method. (b) The OFES meridional transport is calculated based on the OFES-simulated velocity. (c) Distribution of the depth of vanishing vertical velocity in the OFES simulation. Unit is $\mathrm{km}$. (d) Meridional transport discrepancy based on the function of $z=-H(x, y)$ in $(\mathrm{c})$. The gray shade is negative.

Diagnosis of coarse-resolution ocean model simulation suggests that the simulated North Pacific Ocean circulation is generally in good agreement with the Sverdrup relation (e.g., Jiang et al. 2006). Considering that the OFES simulation is in strict dynamic consistency with the NECP winds, the difference between the coarse- and fine-resolution models is suggested to be the reason for the discrepancy of the Sverdrup relation. Ocean nonlinearity is a natural candidate of the cause of the discrepancy.

Finally, as a demonstration of the insensitivity of the meridional transport discrepancy to the choice of $H$, we have calculated the depth of vanishing vertical velocity $\left(|w|<10^{-9} \mathrm{~cm} \mathrm{~s}^{-1}\right)$ at each grid point in the OFES simulation. The function of $z=-H(x, y)$ over the tropical North Pacific is shown in Fig. 14c. The meridional transport discrepancy based on this lower bound of vertical integration is shown in Fig. 15d. Again, the same structure as in Figs. 15a and $15 \mathrm{~b}$ reemerge. This insensitivity to the choice of the vertical bound of integration suggests that the discovered discrepancy from the Sverdrup balance in the northwestern tropical Pacific Ocean is robust.

\section{Conclusions}

In this study, absolute geostrophic currents in the North Pacific Ocean are calculated based on the gridded
Argo profiling float data for the period from January 2004 to December 2011 using the P-vector method. The mean meridional transport of the geostrophic currents is compared with the Sverdrup transport in the North Pacific Ocean to assess the accuracy of the Sverdrup theory. The results have shown large differences from the Sverdrup balance in the regions of $6^{\circ}-12^{\circ} \mathrm{N}, 15^{\circ}-$ $20^{\circ} \mathrm{N}$, and in the recirculation and extension areas of the Kuroshio in the northwestern Pacific Ocean. Analyses suggest that the deviation from the Sverdrup balance is statistically significant and is supported by both the Argo and the WOAO9 data. The pattern of the discrepancy from the Sverdrup balance is independent of the depth of vertical integration and wind stress products used to estimate the Sverdrup transport. These facts suggest that the difference of the geostrophic meridional transport from the Sverdrup balance is robust and structural and that wind stress errors are not the main reason for the large differences. A comparison of the geostrophic meridional transport and Sverdrup transport in the highresolution OFES simulation shows a similar difference. Considering that the wind stress forcing is in strict dynamic consistency with the ocean circulation in OFES, it is speculated that nonlinear effects of the ocean circulation are the reason for the differences. The results suggest that the linear dynamics of the Sverdrup theory are deficient in explaining the meridional transport in the tropical northwestern Pacific Ocean. 
The basin-scale synchronized profiling of the North Pacific Ocean temperature and salinity has been realized for the first time in history by the Argo project. The geostrophic currents based on these Argo profiles suggest stronger mean surface zonal currents of the NEC and NECC than those based on the traditional ship-based WOA09 data. In particular, a subsurface westward current underneath the NECC is found in the Argo geostrophic currents, which is absent in the WOA09 data. The current originates east of the date line and gets intensified toward the western North Pacific Ocean. The average core of this subsurface current is located at the depth range of $200-500 \mathrm{~m}$ and between $4^{\circ}$ and $6^{\circ} \mathrm{N}$, with the maximum amplitude of the westward mean zonal current exceeding $2 \mathrm{~cm} \mathrm{~s}^{-1}$ and a mean zonal transport of more than $4.2 \mathrm{~Sv}$ to the west between $3^{\circ}$ and $7^{\circ} \mathrm{N}$. We name this current the North Equatorial Subsurface Current.

Acknowledgments. This work is supported by National Basic Research Program of China (Project 2012CB956000), by the NSFC Grants 40888001 and 41176019, by CMA Grant GYHY201306018, and by
CAS Strategic Priority Project XDA11010301. Z. Zhang is supported by KLOCAW Grant 1208 and by Zhoushan Municipal Science and Technology Project (2011C32015, 2012C33033). P. C. Chu was supported by the Naval Oceanographic Office. W. K. Dewar is supported by NSF Grants OCE-0960500 and OCE-1049131.

\section{APPENDIX A}

\section{Consistency of P-Vector Method with the $\beta$-Spiral Method}

The P-vector method assumes steady-state circulation along isopycnal surfaces, that is,

$$
\frac{d \rho}{d t}=u \frac{\partial \rho}{\partial x}+v \frac{\partial \rho}{\partial y}+w \frac{\partial \rho}{\partial z}=0 .
$$

Taking the Boussinesq and geostrophic approximations, the thermal wind relation suggests $(\partial u / \partial z)(\partial \rho / \partial x)+$ $(\partial v / \partial z)(\partial \rho / \partial y)=0$. The conservation of potential vorticity gives

$$
\begin{aligned}
\frac{d}{d t}\left(\frac{f}{\rho} \frac{\partial \rho}{\partial z}\right) & =\frac{1}{\rho} \frac{\partial \rho}{\partial z} \beta v+\frac{f}{\rho}\left(u \frac{\partial^{2} \rho}{\partial x \partial z}+v \frac{\partial^{2} \rho}{\partial y \partial z}+w \frac{\partial^{2} \rho}{\partial z \partial z}\right) \\
& =\frac{1}{\rho} \frac{\partial \rho}{\partial z} \beta v+\frac{f}{\rho}\left[\frac{\partial}{\partial z}\left(u \frac{\partial \rho}{\partial x}+v \frac{\partial \rho}{\partial y}+w \frac{\partial \rho}{\partial z}\right)-\frac{\partial u}{\partial z} \frac{\partial \rho}{\partial x}-\frac{\partial v}{\partial z} \frac{\partial \rho}{\partial y}-\frac{\partial w}{\partial z} \frac{\partial \rho}{\partial z}\right] \\
& =\frac{1}{\rho} \frac{\partial \rho}{\partial z} \beta v+\frac{f}{\rho}\left(-\frac{\partial w}{\partial z} \frac{\partial \rho}{\partial z}\right)=0
\end{aligned}
$$

Thus, in a stratified ocean, $\beta v=f(\partial w / \partial z)$, which is the vorticity balance of the $\beta$-spiral method.

\section{APPENDIX B}

\section{The Principles of the P-Vector Method}

The P-vector method is based on the conservation of potential density and potential vorticity [Eqs. (B1) and (B2)] under two approximations: the geostrophic balance and the Boussinesq approximation. The thermal wind vector [Eqs. (B4) and (B5)] between any two levels, $z_{k}$ and $z_{m}$, can be used to calculate the magnitudes of the geostrophic currents at the two levels:

$$
\begin{aligned}
v \cdot \nabla \rho & =0, \\
v \cdot \nabla q & =0, \\
q & =\frac{f}{\rho} \frac{\partial \rho}{\partial z},
\end{aligned}
$$

$$
\begin{aligned}
& \Delta u=\frac{g}{f \rho_{0}} \int_{z_{m}}^{z_{k}} \frac{\partial \rho}{\partial y} d z, \text { and } \\
& \Delta v=-\frac{g}{f \rho_{0}} \int_{z_{m}}^{z_{k}} \frac{\partial \rho}{\partial x} d z .
\end{aligned}
$$

Two necessary conditions must be satisfied for validity of the P-vector method:

(i) the $\rho$ surface is not parallel to the $q$ surface:

$$
\nabla \rho \times \nabla q \neq 0 ; \quad \text { and }
$$

(ii) the velocity $(u, v)$ should execute a $\beta$ spiral at any two levels $\left(z=z_{k}\right.$ and $\left.z=z_{m}\right)$ :

$$
\left|\begin{array}{ll}
u^{k} & v^{k} \\
u^{m} & v^{m}
\end{array}\right| \neq 0
$$

Thus, a unit vector $\mathbf{P}$ can be defined as 


$$
\mathbf{P}=\frac{\nabla \rho \times \nabla q}{|\nabla \rho \times \nabla q|},
$$

which is the intersection of isopycnal and equal potential vorticity surfaces. The geostrophic currents $\mathbf{V}=(u, v, w)$ are assumed to follow the unit vector $\mathbf{P}$, that is,

$$
\mathbf{V}=\mathbf{r}(x, y, z) \mathbf{P},
$$

where $\mathbf{r}$ is the proportionality coefficients. The thermal wind relation at two different depths $z_{k}$ and $z_{m}$ suggests a set of algebraic equations to determine the coefficients r:

$$
\begin{aligned}
& r^{k} p_{x}^{k}-r^{m} p_{x}^{m}=\Delta u_{\mathrm{km}} \\
& r^{k} p_{y}^{k}-r^{m} p_{y}^{m}=\Delta v_{\mathrm{km}} .
\end{aligned}
$$

The determinant of Eq. (B10) is

$$
\left|\begin{array}{ll}
p_{x}^{k} & p_{x}^{m} \\
p_{y}^{k} & p_{y}^{m}
\end{array}\right|=\sin \left(\alpha_{\mathrm{km}}\right)
$$

where $a_{\mathrm{km}}$ is the $\beta$-spiral turning angle between $\mathbf{P}^{k}$ and $\mathbf{P}^{m}$ at the two levels $z_{k}$ and $z_{m}$. In practice, the least squares fitting is used to determine the coefficients $\mathbf{r}$ using data of multiple levels.

\section{REFERENCES}

Antonov, J. I., and Coauthors, 2010. Salinity. Vol. 2, World Ocean Atlas 2009, NOAA Atlas NESDIS 69, 184 pp.

Böning, C. W., R. Döscher, and H. J. Isemer, 1991: Monthly mean wind stress and Sverdrup transports in the North Atlantic: A comparison of the Hellerman-Rosenstein and Isemer-Hasse climatologies. J. Phys. Oceanogr., 21, 221-235.

Chu, P. C., 1995: P-vector method for determining absolute velocity from hydrographic data. Mar. Technol. Soc. J., 29, 3-14.

- 2000: P-vector spiral and determination of absolute velocities. J. Oceanogr., 56, 591-599.

— 2006: P-Vector Inverse Method. Springer, $605 \mathrm{pp}$.

— C. Fan, C. J. Lozano, and J. L. Kerling, 1998: An airborne expendable bathythermograph survey of the South China Sea, May 1995. J. Geophys. Res., 103 (10), 21 637-21 652.

—, J. Lan, and C. W. Fan, 2001: Japan Sea circulation and thermohaline structure. Part I: Climatology. J. Phys. Oceanogr., 31, 244-271.

Cravatte, S., W. S. Kessler, and F. Marin, 2012: Intermediate zonal jets in the tropical Pacific Ocean observed by Argo floats. J. Phys. Oceanogr., 42, 1475-1485.

Davis, R. E., 1976: Predictability of sea surface temperature and sea level pressure anomalies over the North Pacific Ocean. J. Phys. Oceanogr., 6, 249-266.

Foreman, R. J., and S. Emeis, 2010: Revisiting the definition of the drag coefficient in the marine atmospheric boundary layer. J. Phys. Oceanogr., 40, 2325-2332.
Garratt, J. R., 1977: Review of drag coefficients over ocean and continents. Mon. Wea. Rev., 105, 915-929.

Hautala, S. L., D. H. Roemmich, and W. J. Schmitz Jr., 1994: Is the North Pacific in Sverdrup balance along $24^{\circ}$ N? J. Geophys. Res., 99 (C8), 16041-16052.

Hu, D. X., M. Cui, T. Qu, and Y. Li, 1991: A subsurface northward current off Mindanao identified by dynamic calculation. Oceanogr. Asian Marginal Seas, 54, 359-365.

Jiang, H., H. Wang, J. Zhu, and B. Tan 2006: Relationship between real meridional volume transport and Sverdrup transport in the north subtropical Pacific. Chin. Sci. Bull., 51, 1757-1760.

Kessler, W. S., M. C. Spillane, M. C. McPhaden, and D. E. Harrison, 1996: Scales of variability in the equatorial Pacific inferred from tropical atmosphere-ocean buoy array. J. Climate, 9, 2999-3024.

Large, W. G., and S. Pond, 1981: Open ocean momentum flux measurements in moderate to strong winds. J. Phys. Oceanogr., 11, 324-336.

Leetmaa, A., P. Niiler, and H. Stommel, 1977: Does the Sverdrup relation account for the mid-Atlantic circulation? J. Mar. Res., 35, 1-10.

Locarnini, R. A., A. V. Mishonov, J. I. Antonov, T. P. Boyer, H. E. Garcia, O. K. Baranova, M. M. Zweng, and D. R. Johnson, 2010: Temperature. Vol. 1, World Ocean Atlas 2009, NOAA Atlas NESDIS 68, 184 pp.

Marchuk, G. I., A. S. Sarkisyan, and V. P. Kochergin, 1973: Numerical methods and results of calculation of flows in a baroclinic ocean. Geophys. Fluid Dyn., 5, 89-100.

Masumoto, Y., and Coauthors, 2004: A fifty-year eddy-resolving simulation of the World Ocean preliminary outcomes of OFES (OGCM for the Earth Simulator). J. Earth Simul., 1, $35-56$.

Meyers, G., 1980: Do Sverdrup transports account for the Pacific North Equatorial Countercurrent. J. Geophys. Res., 85 (2), 1073-1075.

Nitani, H., 1975: Variations of the Kuroshio south of Japan. J. Oceanogr. Soc. Japan, 31, 154-173.

Qiu, B., S. Chen, and H. Sasaki, 2013a: Generation of the North Equatorial Undercurrent jets by triad baroclinic Rossby wave interactions. J. Phys. Oceanogr., 43, 2682-2698.

—, D. L. Rudnick, S. Chen, and Y. Kashino, 2013b: Quasistationary North Equatorial Undercurrent jets across the tropical North Pacific Ocean. Geophys. Res. Lett., 40, 2183 2187, doi:10.1002/grl.50394.

Reid, J. L., Jr., 1961: On the geostrophic flow at the surface of the Pacific Ocean with respect to the 1000-decibar surface. Tellus, 13, 489-502.

Rio, M.-H., and F. Hernandez, 2004: A mean dynamic topography computed over the World Ocean from altimetry, in situ measurements, and a geoid model. J. Geophys. Res., 109, C12032, doi:10.1029/2003JC002226.

Roemmich, D., and J. Gilson, 2009: The 2004-2008 mean and annual cycle of temperature, salinity, and steric height in the global ocean from the Argo program. Prog. Oceanogr., 82, 81-100.

Schmitz, W. J., Jr., J. D. Thompson, and J. R. Luyten, 1992: The Sverdrup circulation for the Atlantic along $24^{\circ} \mathrm{N}$. J. Geophys. Res., 97 (C5), 7251-7256.

Schott, F., 1939: Die aquatorialen strommungen des westlichen Stillen Ozeans. Ann. Hydrogr. Marit. Meteor., 67, 247-257. , and H. Stommel, 1978: Beta spirals and absolute velocities in different oceans. Deep-Sea Res., 25, 961-1010. 
Stommel, H., and F. Schott, 1977: The beta spiral and the determination of the absolute velocity field from hydrographic station data. Deep-Sea Res., 24, 325-329.

Sverdrup, H. U., 1947: Wind-driver currents in a baroclinic ocean; with application to the equatorial current of the eastern $\mathrm{Pa}$ cific. Proc. Natl. Acad. Sci. USA, 33, 318-326.

Wunsch, C., 1978: The general circulation of the North Atlantic west of $50^{\circ} \mathrm{W}$ determined from inverse method. Rev. Geophys., 16, 583-620.

[-, 2011: The decadal mean ocean circulation and Sverdrup balance. J. Mar. Res., 69, 417-434.
— and D. Roemmich, 1985: Is the North Atlantic in Sverdrup balance? J. Phys. Oceanogr., 15, 1876-1880.

Wyrtki, K., 1961: Physical oceanography of the Southeast Asian waters. Scripps Institute of Oceanography NAGA Rep. 2, 225 pp.

Zhang, Z. C., 2011: The zonal and meridional volume transport of circulation in the tropical northwestern Pacific Ocean (in Chinese with English an abstract). Ph.D. dissertation, Institute of Oceanology, Chinese Academy of Sciences, $74 \mathrm{pp}$.

- D. L. Yuan, and P. C. Chu, 2013: Geostrophic meridional transport in tropical northwest Pacific based on Argo profiles. Chin. J. Oceanol. Limnol., 31, 656-664. 